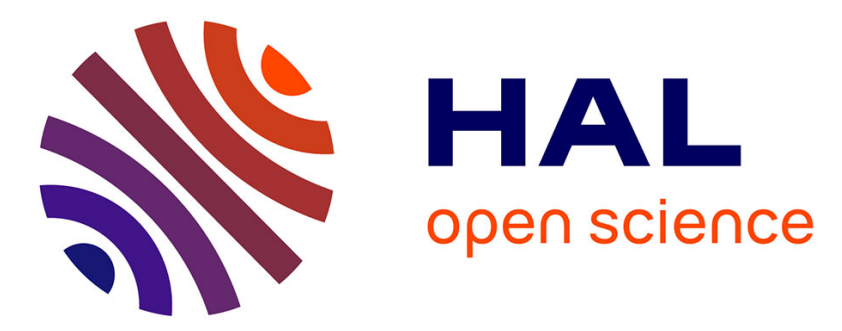

\title{
Real-time diagnostics of a jet engine exhaust using an intra-pulse quantum cascade laser spectrometer
}

Geoffrey Duxbury, Kenneth G. Hay, Nigel Langford, Mark P. Johnson, John D. Black

\section{- To cite this version:}

Geoffrey Duxbury, Kenneth G. Hay, Nigel Langford, Mark P. Johnson, John D. Black. Real-time diagnostics of a jet engine exhaust using an intra-pulse quantum cascade laser spectrometer. Molecular Physics, 2011, 109 (17-18), pp.1. 10.1080/00268976.2011.610367 . hal-00728415

\section{HAL Id: hal-00728415 https://hal.science/hal-00728415}

Submitted on 6 Sep 2012

HAL is a multi-disciplinary open access archive for the deposit and dissemination of scientific research documents, whether they are published or not. The documents may come from teaching and research institutions in France or abroad, or from public or private research centers.
L'archive ouverte pluridisciplinaire HAL, est destinée au dépôt et à la diffusion de documents scientifiques de niveau recherche, publiés ou non, émanant des établissements d'enseignement et de recherche français ou étrangers, des laboratoires publics ou privés. 


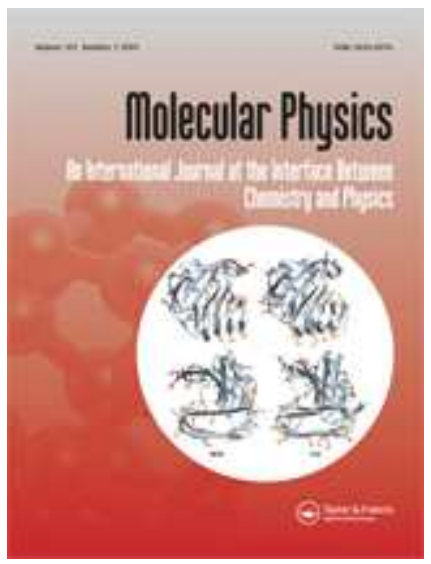

\section{Real-time diagnostics of a jet engine exhaust using an intra- pulse quantum cascade laser spectrometer}

\begin{tabular}{|r|l|}
\hline Journal: & Molecular Physics \\
\hline Manuscript ID: & TMPH-2011-0129.R1 \\
\hline Manuscript Type: & Special Issue Paper - Dijon HRMS \\
\hline Author: & 08-Jul-2011 \\
\hline & $\begin{array}{l}\text { Complete List of Authors: } \\
\text { Jannonon, Mark; Rolls Royce Plc } \\
\text { Bay, Konn; , University of Manchester, School of Electrical and } \\
\text { Electronic Engineering }\end{array}$ \\
\hline Keywords: & $\begin{array}{l}\text { quantum cascade laser, pulsed laser, jet engine exhaust, } \\
\text { combustion, real-time diagnostics }\end{array}$ \\
\hline
\end{tabular}

\section{SCHOLARONE \\ Manuscripts}




\title{
Real-time diagnostics of a jet engine exhaust using an intra- pulse quantum cascade laser spectrometer
}

\author{
Geoffrey Duxbury, ${ }^{1, *}$ Kenneth G. Hay, ${ }^{1,2}$ Nigel Langford, ${ }^{1}$ Mark. P. Johnson ${ }^{3}$ \\ and John D. Black ${ }^{3,4}$ \\ ${ }^{1}$ Department of Physics, University of Strathclyde, John Anderson Building, \\ 107Rottenrow E, Glasgow, G4 ONG, UK \\ ${ }^{2}$ Now at Cascade Technologies, Glendevon House, Castle Business Park, Stirling, \\ FK9 4TZ, UK \\ ${ }^{3}$ Rolls Royce Plc, PO box 31, Derby, DE24 8BJ, UK
}

${ }^{4}$ Present address: School of Electrical and Electronic Engineering, University of Manchester, Manchester M60 1QD, UK

*Corresponding author: g.duxbury@strath.ac.uk

It has been demonstrated that an intra-pulse scanned quantum cascade laser spectrometer may be used to obtain real-time diagnostics of the amounts of carbon monoxide, carbon dioxide, and water, in the exhaust of an aero- gas turbine (turbojet) engine operated in a sea level test cell. Measurements have been made of the rapid changes in composition following ignition, the composition under steady state operating conditions, and the composition changes across the exhaust plume. The minimum detection limit for $\mathrm{CO}$ in a double pass through a typical gas turbine plume of $50 \mathrm{~cm}$ in diameter, with 0.4 seconds integration time, is approximately $2 \mathrm{ppm}$. 


\section{Introduction}

Although emissions from aircraft engines are responsible for a very small part of total atmospheric pollution, they can have a disproportionate effect on the atmosphere [1]. The number of aircraft-miles per year is increasing, as is total aviation fuel consumption. Engine manufacturers are required to measure carbon monoxide $(\mathrm{CO})$, nitric oxide $(\mathrm{NO})$, nitrogen dioxide $\left(\mathrm{NO}_{2}\right)$, unspeciated unburned hydrocarbon, and 'smoke' particles using procedures approved by the UN body,the International Civil Aviation Organisation on each new engine type before it can be certified. These procedures all involve sampling gas from the exhaust plume within half a diameter of the final nozzle while the engine is run on a 'sea level' test bed. Sampling hardware capable of withstanding plume conditions so close to an engine is expensive, samples must be transferred by heated lines to a variety of measuring instruments, creating many measurement uncertainties, and the engine has to be run for a considerable time to be stabilized on the required number of measurement conditions. The overall result is that emissions testing is inconvenient and expensive. Hence, few such tests are carried out.

Atmospheric scientists and agencies such as the National Aeronautics and Space Administration (NASA) and the Environmental Protection Agency (EPA) in the US, and the European Aviation Safety Agency (EASA) in Europe are using the standard techniques to analyze emissions from aircraft on the ground. For example, a wide variety of measurements of emissions from aircraft were carried out by Spicer et al. [2]. Several different measurement methods were used including chemiluminescence, infrared absorption, flame ionization and proton transfer reaction mass spectrometry. These measurements were taken from US military aircraft running at various engine speeds, while on the ground. Gas was sampled from the exhaust 
flow some distance from the engine. Similar work by Agrawal et al. [3] measured emissions at a distance of $1 \mathrm{~m}$ behind a selection of four commercial aircraft engines. Overall, there is a need for many more aircraft emissions measurements, and a desire to move from the traditional gas sampling based methods to non-intrusive (usually spectroscopic) analysis, since optical methods do not disturb the flow pattern.

In 2000 Schäfer and colleagues [4] made a detailed comparison of intrusive measurements, and non-intrusive optical measurements, of aircraft engine emissions. At that time they concluded that the non-intrusive methods could not entirely replace the intrusive methods. Their optical trace gas measurements were made immediately behind the exhaust nozzle of a static aero engine using infrared Fourier transform (FTIR) spectrometers. A more recent EU transport research project, MENELAS, Minority effluent measurements of aircraft engine emissions by infrared laser spectroscopy [5], was also concerned with the measurement of some of the most important aircraft engine exhaust gases using mid-infrared laser sources. Their program report highlighted the future importance of non-intrusive methods, particularly those which use a high repetition rate infrared source for LIDAR measurements.

Tunable diode laser absorption spectroscopy is becoming increasingly used for engineering measurement and diagnostics, Sanders et al. [6] However, there have been a few measurements in exhaust plumes using tunable diode laser absorption [7,8]. Major obstacles have been low sensitivity for many molecules at commonly used near infrared (NIR) laser wavelengths (e.g. NIR communications lasers) and the use of narrow wavelength scan regions so that a range of lasers are required, frequently one laser per molecule. For nitric oxide measurement, a complex UV laser system was required [8]. Quantum cascade (QC) lasers operating at room temperature 
provide access to regions of the spectrum where molecules of interest are strongly absorbing, e.g. Chao, Jeffries and Hanson [9]. In this work, a single laser accessed spectral lines of at least three molecules.

One of the main ways of making measurements with a high repetition rate infrared source is to use a pulsed distributed feedback (DFB) QC laser operating near room temperature $[11,12]$. Owing to the rapid Joule heating the laser output sweeps rapidly to lower frequency, a frequency down chirp, during each pulse. A timeaveraged spectrum are then obtained by the addition of a fixed number of spectra by the fast digitizer. This spectrum is then transferred to the control computer. The resultant spectrum, recorded in the time domain, may be transformed to the frequency (or inverse wavelength) domain by making use of etalon fringes recorded during the down-chirp, together with the tabulated inverse-wavelength $/ \mathrm{cm}^{-1}$ values of absorption lines identified during the scan. As a result of the short time required to record a single spectrum, typically 0.5 to 2 microseconds, intra-pulse scanned lasers have excellent performance characteristics in noisy environments, since each spectrum is acquired in a time shorter than that of most of the noise fluctuations in the system. In this paper will describe one way of exploiting an intra-pulse spectrometer for investigating the change in the concentrations of molecules in a turbojet following ignition.

\section{Experiment}

The present experiments employed a $4.86 \mu \mathrm{m}$ QC laser, with a peak output power of $18.8 \mathrm{~mW}$, mounted in a compact laser head, with a matching driver developed by Cascade Technologies Ltd. The laser operating parameters are given in Table 1 . The detector used is a two stage Peltier cooled photovoltaic mercury cadmium telluride detector, with a built in trans-impedance amplifier (Vigo PVI-2TE- 
$8 \mathrm{MCT})$. For all work, the signals from the photodetector were fed into the control computer through an Acqiris AP200 fast digitizer card (0.5 ns temporal resolution, 8 bits vertical resolution) housed in a PCI slot. This was controlled from LabVIEW 7.1 virtual instruments (VIs), incorporating subVIs supplied by Acqiris.

Figure 1(a) shows the detector and the laser housing mounted on a vertical traverse, in the engine test cell. The laser beam crossed the exhaust plume onto a corner cube reflector, which returned it to the detector via a parabolic mirror. The whole assembly could be moved by the vertical traverse, driven from the control room, to interrogate different horizontal lines-of-sight across the exhaust. As the movement of the vertical traverse is slow, the variation with height of the lines-ofsight measurements were recorded at a fixed engine speed. Laser and detector drive boxes were attached securely to an adjacent table, and the control and detector signal cables were fed to the control computer within the test-bed control room. The schematic layout of the measurement system is shown in Figure 1(b).

The base temperature, Celsius, of the QC laser was set at $-20^{\circ} \mathrm{C}$. The pulse length was set at $1300 \mathrm{~ns}$, the drive voltage was $12 \mathrm{~V}$, and the pulse repetition frequency was $20 \mathrm{kHz}$. Since the AP-200 digitiser has a time resolution of $0.5 \mathrm{~ns}$, each spectrum recorded consists of 2600 data points. The resultant wavenumber down-chirp range of the laser was between $2058.84 \mathrm{~cm}^{-1}$ and $2055 \mathrm{~cm}^{-1}$. The operating parameters of the laser are given in Table 1.

In McCulloch et al. [12] it was shown that, in an intra-pulse QC laser spectrometer, the resolution of an instrument is determined by the frequency chirp rate of the laser and the temporal resolution of the detection system. The product of the equivalent duration, $\Delta t$, and the equivalent bandwidth, $\Delta v$, must exceed or be equal to $C$ i.e $\Delta t \Delta v \geq C$. In a time window $\tau$ the laser frequency will chirp by the 
amount $\frac{d \boldsymbol{v}}{d t} \tau$. The best aperture time is then decided by $\frac{C}{\tau}=\frac{d \boldsymbol{\nu}}{d t} \tau$. Rewriting in terms of $\Delta v, \Delta v=\frac{d v}{d t} \frac{C}{\Delta v}$, i.e. $\Delta v^{2}=\frac{d v}{d t} C$, hence $\Delta v=\sqrt{\frac{d v}{d t} C}$. As a result of experimental measurements of the line shape we have shown that the most appropriate time window is Gaussian, with a value of $C=0.441$.If the laser downchirp rate is $100 \mathrm{MHz} \mathrm{ns}^{-1}$ the calculated full width at half maximum (fwhm) is 210 $\mathrm{MHz}\left(0.007 \mathrm{~cm}^{-1}\right)$, this falls to $94 \mathrm{MHz}\left(0.003 \mathrm{~cm}^{-1}\right)$ at a chirp rate of $20 \mathrm{MHz} \mathrm{ns}{ }^{-1}$.

The background spectra recorded prior to the ignition of the gas turbine, are used to convert the signals to a transmission spectrum. The transmission is taken as the signal divided by the background, and requires the assumption that the laser pulse does not change significantly between the recording of a background spectrum, and the recording of the final spectra which require that background. For this assumption to be valid, the time between background scans must be carefully chosen. It is necessary to balance up the desire for as few breaks in data logging as possible with the need for spectra to match the background signal. In most circumstances, the cooling of the laser housing, and the stability of the laser power supply, is sufficient to prevent any long-term drift of a typical pulsed QC laser. This has been demonstrated in the experiments carried out on the amorphous diamond plasma reactor in the Ashfold group at Bristol University [13], and in measurements of acetylene in flames using “chirp-based quantum cascade laser spectrometry" by Quine and McNesby [14]

\section{Analysis of Chirped Pulse Spectra}

As we have noted in the previous section, a chirped pulse QC laser spectrometer may be used to measure the absorption lines due to several different gaseous 
molecules within its operational micro window of from 2 to $5 \mathrm{~cm}^{-1}$. However, the variation of the intensities of the absorption lines may have a complex temperature dependence. In previous work on the amorphous diamond plasma reactor in at Bristol University [13] we were able to exploit this variation to infer the temperature dependence of the methane/acetylene interchange. However in the present study of the gas turbine plume the situation is more complicated, and, unlike the diamond reactor investigation [13], we do not have a theoretical model of the temperature variation across the plume. Two of the tools which may be used to study the temperature variation of the three main gases which we can detect, carbon monoxide, carbon dioxide and water, are the HITRAN database [15], and the HITEMP database [16]. A computer application available for use with these databases, javaHAWKS [15], enables the temperature dependence of absorption cross sections to be calculated. It also allows an estimate of the temperature dependence of the air broadened collision cross sections to be made. This information is particularly useful in the micro-window used in the diagnostics of the jet engine exhaust, $2055-2059 \mathrm{~cm}^{-}$ 1 , as most of the absorption lines of water which lie within this range belong to hot bands, lines which originate in a rotational level of a vibrationally excited state. In addition one of the two absorption lines of carbon monoxide, which lie within the tuning range of the laser, originates in a rotational level of the first vibrationally excited state. The temperature dependence of the absorption cross sections may also become important. As may be seen from the HITEMP data in Table 2, the absorption lines are predicted to narrow by a factor of up to two as the gas temperature is increased. However, recent calculations by Gamache and Laraia [17 ] have shown that the power law model for the temperature dependence of the linewidth, used in 
both HITRAN and HITEMP, do not give reliable predictions for all transitions of water.

At atmospheric pressure the line shape is almost Lorentzian, as the instrumental broadening due to the fast chirp, and the Doppler broadening, are less than that caused by molecular collisions. A summary of the main absorption lines identified, and the calculated temperature dependence of their integrated absorption and pressure broadening, is given in Table 2, and examples of spectra calculated using the HITEMP data are given in the next section.

\section{Results}

The measurements of the absorption spectra were made during a series of five runs of the gas turbine within a single day in July 2009. In each of these runs, two types of spectra were recorded, a time series of spectra in which the changes in the total transmission, at a fixed height of the laser beam, were recorded, and a series of transect scans in which the spectra were recorded as laser beam height was varied from the centre to the periphery of the exhaust plume. In these transect scans, the path length variation of the transmission spectra is recorded. In order to demonstrate the very different temperature dependence of the spectra of carbon monoxide, water and carbon dioxide in Figures 2 and 3 we have shown the resultant changes in the calculated temperature dependence of the transmission spectra of individual molecules in Figure 2, and overlaid spectra of the three gases, at a set temperature in Figure 3. The path lengths and partial pressures of the molecules used for the calculations are given in Table 3, with the line positions and absorption cross sections being taken from HITEMP2010 [16]. The product of path length and partial pressure was chosen so that the resultant calculated transmission spectra approximately 
matched those recorded experimentally. In the calculated spectra in Figure 2 (a), within our measurement wavenumber window, the absorption by water is very low at $400 \mathrm{~K}$. The intensities of the water lines increase rapidly with temperature to be readily visible at $700 \mathrm{~K}$, and becomes one of the major features at $1000 \mathrm{~K}$. The calculated spectrum of carbon monoxide, Figure 2(b), consists principally of two features which are strongly temperature dependent, a line from the fundamental band of $\mathrm{CO}, 1-0$, and a weaker one originating in the first vibrational state, 2-1. In addition there are two weak absorption lines of the ${ }^{13} \mathrm{C}^{16} \mathrm{O}$ and ${ }^{12} \mathrm{C}^{17} \mathrm{O}$ isotopologues, which exhibit little temperature dependence. The maximum absorbance of carbon dioxide shown in Figure 2(c) decreases with increasing temperature, and at the higher temperatures the spectrum component due to carbon dioxide becomes weaker and more complex owing to the large number of hot-band lines, which increase in strength as the temperature rises. In Figure 3(a), at a temperature of $400 \mathrm{~K}$, only the strong fundamental line of $\mathrm{CO}$ and the weak isotopic feature may be seen, as are two lines of carbon dioxide. However, at a temperature of $700 \mathrm{~K}$, the spectrum is dominated by absorption lines of $\mathrm{CO}$ and $\mathrm{H}_{2} \mathrm{O}$, with the lines of $\mathrm{CO}_{2}$ being much less apparent. Finally at $1000 \mathrm{~K}$, the most obvious absorption lines are those of $\mathrm{CO}$ and $\mathrm{H}_{2} \mathrm{O}$, with an interesting "signature pair", close to $2056 \mathrm{~cm}^{-1}$. It is this "signature pair" which play a key role in aiding our understanding of the patterns seen in the experimental spectra.

In the five experimental runs, variations in the engine performance were made to test the behaviour of one set of instruments, belonging to the principal research group, which were attached directly to the engine housing. These changes in engine performance caused a considerable variation in the quality of the spectra obtained. As a result of this variation we have chosen to concentrate on two, Runs 3 and 5, which were recorded under similar operating conditions apart from the number of spectra 
averaged. In Run 3, 8000 successive spectra were co-added giving a total integration time of 0.4 seconds, whereas in Run 5, 4000 spectra were co-added, with a resultant integration time of 0.2 seconds.

In Figure 4 the time history of the turbine speed recorded in run 5 and the gas temperature measured by a thermocouple at turbine exit in these runs, are given. Recently Massini et al. [18] measured the temperature of the engine exhaust, and compared the results obtained using their probe with the readings of the reference thermocouples. The temperature range which they measured, from ambient to $873 \mathrm{~K}$, is very similar to that recorded in Figure 4. On these figures we have indicated the regions to which the QC spectra presented in Figures 5 and 6 are related.

In Figure 5 we have given examples of the development of the initial temperature dependent patterns of the absorptions lines of $\mathrm{CO}, \mathrm{H}_{2} \mathrm{O}$ and $\mathrm{CO}_{2}$ following the start up of the turbojet. Spectra 5(a) to 5(c) are from Run 3, and 5(d) is from Run 5. Figure 6 shows the development of the final intensity pattern in Run 5 at steady running at $12,700 \mathrm{rpm}$.

When each engine test begins, the gas turbine blades are set into motion before the ignition of the gas mixture occurs. There is no direct indication of the ignition time in the information presented on line in the control room. Before ignition of the gas turbine fuel occurs, there are no absorption lines visible in the spectrum recorded with a $1 \mathrm{~m}$ absorption path at atmospheric pressure within the test cell shown in Figure 1(a). The time following ignition is therefore calculated by back extrapolation from the time at which the first strong CO line is recorded, using the initial almost linear increase with time of the absorption of the strongest CO line.

The experimental spectra recorded in Runs 3 (R3) and 5 (R5), are compared with those calculated using the HITRAN and HITEMP databases [14,15], and shown 
in Figures 2 and 3. In calculating the time dependence of the absorption spectra, following ignition, we have made the following assumptions: the initial concentrations of the gases may be inferred by matching the calculated transmission spectra with the experimental spectra recorded when the carbon dioxide absorption became stationary; the subsequent behaviour may be modeled by fixing the gas amounts at their initial values, and calculating the resultant temperature dependence of the transmission spectra, taking into account both the temperature dependence of the absorption cross sections and also that of the pressure broadened line widths. We have used a total path length of $1 \mathrm{~m}$, and have evaluated a total absorption cross section assuming a constant absorbance per unit path length. The initial parameters used in the calculations are given in Table 3. In Table 3 we have also given the parameters assuming a total path length through the plume only, $0.882 \mathrm{~m}$, and in the absence of a temperature gradient within the plume. The temperature dependent absorption cross sections, full width at half maximum (fwhm), were based on the values for the half width at half maximum (hwhm) given in HITRAN and HITEMP.

In Figure 5(a), and 5(b) the transmission spectra recorded within the first 1.6 seconds after ignition are shown. The pattern seen is very similar to that in the model spectrum in Figure 3(a), where the absorption by carbon dioxide may be clearly seen, that of the strongest water line is just visible, and the strongest absorption is that of CO. In Figure 5(c), with sample spectra recorded up to 37 seconds from the first recorded signal, the fingerprint spectra of the bands of water and the hot band of carbon monoxide are very similar to those in the calculated high temperature spectrum shown in Figure 3(c). In Figure 5(d) we show spectra in Run 5 recorded within a similar time window to that in Fig 5(c). The reproducibility of the spectral 
patterns recorded in two separate runs shows the reliability of this method of measuring combustion processes.

The maximum absorption by the hot band lines occurs within 37 seconds of the recording of the first absorption by carbon monoxide. The characteristic fingerprint pattern is shown in Figure 6 for R5. After ca. 250 seconds the ratio of the intensities of the two fingerprint features of hot carbon monoxide and hot water stabilizes, and appears to remain almost constant throughout the remainder of the tests during which the rpm rate of the engine was increased. The main effect of the increased engine speed appears to be the increasing fluctuations observed in the experimental spectra. On the basis of the minimal changes measured absorption of $\mathrm{CO}, \mathrm{CO}_{2}$ and $\mathrm{H}_{2} \mathrm{O}$ the gas concentrations appear to be static during the majority of each test cycle during which the rpm rate of the engine was increased.

In Figure 7 we show a schematic diagram of the path length through the exhaust plume as a function of traverse height, for the spectra displayed in Figure 8. In Figure 8 we show examples of part of the transmission spectrum recorded in run 5 in the transect scan under steady conditions of $12,700 \mathrm{rpm}$. The effective path lengths range from $269 \mathrm{~mm}$ where a spectrum of only strong CO line was recorded, to 878 $\mathrm{mm}$ when the spectra also included lines due to hot $\mathrm{CO}$ and hot water. In Fig. 8(a) spectra are dominated by the strong absorption line of cold CO. Although initially its absorption increases rapidly as the path length through the plume increases, it appears to be static as the path length is increased from 738 to $878 \mathrm{~mm}$. In Figure 8 (b) we show an expanded plot in which the variation with path length of the absorption of hot $\mathrm{CO}$ and hot water may be seen. At $371 \mathrm{~mm}$ path length the two spectra appear to have similar amplitude. As the path length is increased to $444 \mathrm{~mm}$, and the laser beam samples part of the exhaust closer to its centre, the absorption of the $\mathrm{CO}$ increases 
faster than that of the water. However as the path length is further increased, and the beams probes closer to the core of the exhaust, the absorption of light by the water increases faster than that by $\mathrm{CO}$, so that at $20 \mathrm{~mm}$ from the start of the transect, with a total path length of $878 \mathrm{~mm}$, the peak absorption of the $\mathrm{CO}$ and water are almost identical.

The profile of gas species concentration [19] or soot particle concentration [20] in the exhaust of mixed flow turbofan aero-engine, which should be similar to the profile of a turbojet, can be represented by a 'flat-topped', or truncated, Gaussian. That is, in the centre of the plume concentrations are homogeneous while around the edges concentrations, and presumably temperatures, fall off in a Gaussian manner until they reach ambient levels, as shown in Figure 9. When the laser traverses the plume 210 $\mathrm{mm}$ above the central plane (269 $\mathrm{mm}$ path length), it intersects the Gaussian edge where temperature is falling rapidly. Hence, the only line visible in the spectrum is the CO 1-0 line. As the beam is moved closer to the central plane, it passes through hotter regions with higher $\mathrm{CO}$ and $\mathrm{H}_{2} \mathrm{O}$ concentrations. By $200 \mathrm{~mm}$ the $\mathrm{H}_{2} \mathrm{O}$ II and CO 2-1 lines are clearly visible and the cold CO 1-0 line is stronger because the CO concentration has increased. Moving further towards the centre, all lines increase in intensity as the pathlength through hot gas gets longer, with the rate of change becoming smaller close to centre.

\section{Summary and Conclusions}

In this paper we have demonstrated that it is possible to use an intra-pulse quantum cascade laser spectrometer to record high resolution absorption spectra through a gas turbine plume. We believe that the reason for the good signal to noise ratio is related to the rapid acquisition rate of a single spectrum, 1.3 microseconds, so that when the spectra are co-added the resultant noise reduction is proportional to, 
$\sqrt{N}$ where $\mathrm{N}$ is the number of spectra averaged. This level of noise reduction was previously demonstrated in laboratory experiments by McCulloch et al. [11]. A way in which the stored, averaged spectra, may exhibit rapid baseline oscillations is as a result of refractive index fluctuations within the exhaust plume, which become more important at higher turbine speeds.

Since their original studies of the use of Fourier transform spectrometers for non-intrusive measurements of gas turbine exhaust composition, Schäfer and his colleagues [19] have improved their multiple pass optical system for use in turbine test beds. Using an optimum of 18 passes through a $50 \mathrm{~cm}$ diameter gas turbine plume they were able to obtain accurate mixing ratios. From their spectra it is possible to see the level of acoustic noise in the frequency range of 200 to $400 \mathrm{~Hz}$ which they have subsequently eliminated. They are also sensitive to the infrared emission from the plume into their Fourier spectrometer. The rapid sampling rate of the QC spectrometer, and the much smaller acceptance angle of the fast detector used, minimizes both the vibration and the infrared emission problems, and helps to enhance the quality of the spectra recorded. The minimum detection limit, set by the average noise in the co-added spectra of $\mathrm{CO}$, using a double pass through the plume, is ca $2 \mathrm{ppm}$ for $\mathrm{CO}$.

\section{Acknowledgements}

We are indebted NERC for the award of a COSMAS grant, and to the EPSRC for an instrumentation grant, and for the award, to K.G. Hay, of a studentship through the Doctoral Training account. GD is grateful to the Leverhulme Trust for the award of an 
Emeritus Followship and JDB to the Royal Society for the award of an Industry Fellowship. We would also like to thank Dr M. Christodoulou and his team at Scitek Consultants for their help in fabricating, assembling, and testing, the rig used for making the experimental measurements, and Rolls-Royce for their support and the use of their test Facilities. 


\section{References}

1. U. Schumann, Annales Geophysicae 12, 365-384 (1994).

2. Chester W. Spicer, Michael W. Holdren, Kenneth A. Cowen, Darrell W. Joseph, Jan Satola, Bradley Goodwin, Howard Mayfield, Alexander Laskin, M. Lizabeth Alexander, John V. Ortega, Matthew Newburn, Robert Kagann and Ram Hashmonay Atmospheric Environment, 43, 2612-2622, (2009)

3. Harshit Agrawal, Aniket A. Sawant, Karel Jansen, J. Wayne Miller and David R. Cocker III, Atmospheric Environment, 42, 4380-4392, (2008)

4. Klaus Schäfer, Jörg Heland, Dave H. Lister, Chris W. Wilson, Roger J. Howes, Robert S. Falk, Erwin Lindermeir, Manfred Birk, Georg Wagner, Peter Haschberger, Marc Bernard, Olivier Legras, Peter Wiesen, Ralf Kurtenbach, Klaus J. Brockmann, Volker Kriesche, Moira Hilton, Gary Bishop, Roy Clarke, John Workman, Michael Caola, Rachel Geatches, Roger Burrows, John D. Black, Philippe Hervé and Johanna Vally” Appl. Opt., 39, 441-455 (2000).

5. ONERA Physics and Instrumentation Department, Minority effluent measurements of aircraft Engine emissions by infrared Laser Spectroscopy (MENELAS) project Final Technical Report, RF 3/07279 DMPH September 2006 (www.transport-research.info)

6. Scott.T. Sanders, Daniel W. Mattinson, L.Ma, J.B. Jeffries and Ronald K. Hanson, Optics Express, 10, 505 (2002)

7. Thomas N. Anderson, Robert P. Lucht, Rodolfo Barron-Jimenez, Sherif F. Hanna, Jerald A. Caton, Thomas Walther, Sukesh Roy, Michael S. Brown, 
James R. Gord, Ian Critchley, and Luis Flamand, Appl. Opt. 44, 1491-1502 (2005)

8. M.G. Allen, B.L. Upschulte, D.M Sonnenfroh, W.J. Kessler and P.A. Mulhall,. AIAA-2000-2452 et al. 2000. “Overview of diode laser measurements in large-scale test facilities”. $21^{\text {st }}$ AIAA Aerodynamic Measurement Technology and Ground Testing Conference, June 19-22, 2000, Denver, CO.

9. Xing Chao, Jay. B. Jeffries, Ronald K. Hanson, Proc. Comb. Inst. (2010) doi:10.1016/j.proci.2010.05.014

10. Geoffrey Duxbury, Nigel Langford, Michael T. McCulloch and Stephen Wright, Chem. Soc. Rev. 34, 921-934 (2005)

11. Michael T. McCulloch, Nigel Langford and Geoffrey Duxbury, Appl. Opt., 44, 2887-2894 (2005).

12. Michael T. McCulloch, Erwan L. Normand, Nigel Langford, Geoffrey Duxbury and D.A. Newnham, J. Opt. Soc. Am. B, 20,1761 (2003)

13. Jie Ma, Andrew Cheesman, Michael N.R. Ashfold, Kenneth.G. Hay, Stephen Wright, Nigel Langford, Geoffrey Duxbury and Yuri A. Mankelevich, J. Appl. Phys. 106, 033505 1-15 (2009)

14. Zachary R. Quine and Kevin L. McNesby. Appl. Opt, 48, 3075-3083 (2009)

15. L. S. Rothman, A. Barbe, D. C. Benner, L. R. Brown, C. Camy-Peyret, M.R. Carleer, K. Chance, C. Clerbaux, V. Dana, V. M. Devi, J.-M. Flaud, R. R. Gamache, A. Goldman, D. Jacquemart, K. W. Jucks, W. J. Lafferty, J.-Y. Mandin, S. T. Massie, V. Nemtchinov, D. A. Newnham, A. Perrin, C. P. Rinsland, J. Schroeder, K. M. Smith, M. A. H. Smith, K. Tang, R. A. Toth, J. Vander Auwera, P. Varanasi, and K. Yoshino, “ The HITRAN molecular 
spectroscopic database:edition of 2000 including updates through 2001", J. Quant. Spectrosc. Radiat. Transf. 82, 5-44 $\square(2003)$.

16. L. S. Rothman, I.E. Gordon, R.J. Barber, H. Dothe, R. R. Gamache, A. Goldman, V.I. Perevalov, S.A. Tashkun, J. Tennyson, "HITEMP, the high temperature molecular spectroscopic database”, J. Quant. Spectrosc. Radiat. Transf. 111, 2139-2150 $\square(2010)$

17. Robert R. Gamache and Anne.L. Laraia, J. Lol. Spectrosc, 257, 116-127 (2009)

18. Michaela Massini, Robert J. Miller, Howard P. Hodson and Nick Collings, Proc. of ASME Turbo Expo 2010GT 2010 June 14 -18, 2010 Glasgow. UK.

19. Klaus Schäfer, Klaus Brockmann, Jörg Heland,Peter Wiesen, Carsten Jahn and Olivier Legras.,, Appl. Opt., 44, 2189-2201 (2005).

20. John D. Black and Mark P. Johnson, Aerospace Science and Technology, 14, $329-337$ (2010). 


\section{Figure Captions}

Figure 1 (Color online)

Experimental Layout

(a) Photograph of spectrometer system in test cell

(b) Schematic diagram of the spectrometer arrangement.

Figure 2

Calculated temperature-dependent spectra of $\mathrm{CO}, \mathrm{CO}_{2}$ and $\mathrm{H}_{2} \mathrm{O}$ within the tuning range used in the turbojet exhaust experiments, 2044.9 to $2058.9 \mathrm{~cm}^{-1}$. The temperatures chosen were 400,700 and $1000 \mathrm{~K}$. The absorption cross sections used were extracted from HITEMP2010 [15] by using “javaHAWKS” [14]. The other parameters used are given in Table 4.

(a) Water, (b) carbon monoxide and (c) carbon dioxide.

Figure 3

Calculated temperature dependent spectra of the turbojet exhaust with spectra of $\mathrm{H}_{2} \mathrm{O}$, $\mathrm{CO}$ and $\mathrm{CO}_{2}$ overlaid. The temperatures chosen to demonstrate the complexity of the resultant temperature-dependent spectral fingerprints were (a) $400 \mathrm{~K}$, (b) $700 \mathrm{~K}$ and (c) $1000 \mathrm{~K}$.

Figure 4

Variation of the engine speed (rpm) (heavy line), and the plume temperature (thin line), of Run 5 with time(1) $t=0$ s; (2) end of scan range in Figure 5 (d), (3) end of scan range in Figure 6, (4) Location of transect scans of Figure 8 at 12,700 rpm. 


\section{Figure 5}

Development of the initial temperature dependent patterns of the absorption lines of $\mathrm{CO}, \mathrm{H}_{2} \mathrm{O}$ and $\mathrm{CO}_{2}$ following start up of the turbojet.

(a) Lines in Run 3 at threshold, (i) background, (ii) after 0.4 s, CO only; (ii) after $0.8 \mathrm{~s}, \mathrm{CO}, \mathrm{CO}_{2}$, and a very weak line of water.

(b) Run 3, variation of the strength of the absorption lines of the gases, (i) background, (ii) $2.8 \mathrm{~s}$, (iii) $4.8 \mathrm{~s}$ and (iv) $8.8 \mathrm{~s}$.

(c) Run 3, development of the characteristic patterns of the absorption lines of hot water $\left(\mathrm{H}_{2} \mathrm{O}\right.$ I and II) and hot carbon monoxide (CO 1-0). (i) background, (ii) $8.8 \mathrm{~s}$, (iii) $16.8 \mathrm{~s}$ and (iv) $36.8 \mathrm{~s}$.

(d) Run 5, a comparison start up spectrum to that in Fig 5 (c), showing the reproducibility of the development of the characteristic patterns of the absorption lines of hot water $\left(\mathrm{H}_{2} \mathrm{O}\right.$ I and II) and hot carbon monoxide (CO 10). (i) background, (ii) $5.2 \mathrm{~s}$, (iii) $16.2 \mathrm{~s}$ and (iv) 36.2 .

Figure 6

Run 5, the development of the final intensity pattern of the features of hot water and hot carbon monoxide as steady running at $12,700 \mathrm{rpm}$ is approached. (i) background, (ii) $26.2 \mathrm{~s}$, (iii) $36.2 \mathrm{~s}$ and (iv) $226.2 \mathrm{~s}$

Figure 7 (Color online)

A schematic diagram to show the variation of the observation path length through the exhaust plume as a function of the distance from the central axis of the plume. The path lengths shown are those for the spectra of Figure 8. 
Figure 8 (Color online)

Run 5, using steady operating conditions of 12,700 rpm as shown in Figure 4. The spectra through the plume were recorded by varying the height of the beam traversing the plume. The variation of the absorption cross sections of the main line of $\mathrm{CO}(1-0)$ and the line of hot $\mathrm{CO}(2-1)$ and the two overlapping lines of hot water, $\mathrm{H}_{2} \mathrm{O}$ II, are shown.

(a) Full transmission range. (i) $210 \mathrm{~mm}, 269 \mathrm{~mm}$ path length, (ii) $200 \mathrm{~mm}$ height, $371 \mathrm{~mm}$ path length; (iii) $195 \mathrm{~mm}$ height, $415 \mathrm{~mm}$ path length; (iv) $190.4 \mathrm{~mm}$ height, $445 \mathrm{~mm}$ path length; (v) $120.7 \mathrm{~mm}$ height, $738 \mathrm{~mm}$ path length; (vi), 20.4 $\mathrm{mm}$ height, $878 \mathrm{~mm}$ path length.

(b) Expanded view to show the different variation with path length of the intensities of the $\mathrm{H}_{2} \mathrm{O}$ II and $\mathrm{CO} 2-1$ lines. The scans are numbered as in Figure8 (a). Note the rapid increase in the strength of the water absorption line II from (iv) to (vi). Figure 9 (Color online)

A schematic diagram of a flat topped Gaussian profile model of an exhaust. 


\section{Tables}

Table 1 Operating parameters of the Quantum Cascade laser spectrometer

\begin{tabular}{ll}
\hline Laser wavelength & $4.86 \mu \mathrm{m}$ \\
\hline Peak output power & $18.8 \mathrm{~mW}$ \\
\hline Frequency downchirp duration & $1.3 \mu \mathrm{s}$ \\
\hline Number of data points & 2600 \\
\hline Start chirp rate / MHz/ns & 321.3 \\
End chirp rate / MHz/ns & 51.2 \\
Chirp range / cm ${ }^{-1}$ & 5.06 \\
Temperature tuning / $\mathrm{cm}^{-1}$ & 9.74 \\
Highest wavenumber / cm & \\
Repetition frequency/kHz & 2058.72 \\
Number of spectra averaged per spectrum & Run 3, 8000 \\
& Run 5, 4000 \\
\hline
\end{tabular}


Table 2 Identified lines of $\mathrm{CO}_{2}, \mathrm{CO}$ and $\mathrm{H}_{2} \mathrm{O}$, and their temperature variation.

\begin{tabular}{|c|c|c|c|c|c|}
\hline $\begin{array}{l}\text { Wavenumber } \\
/ \mathrm{cm}^{-1}\end{array}$ & $\begin{array}{l}\text { Vibrational } \\
\text { transition }\end{array}$ & Rotational transition & $\begin{array}{l}\text { Line Intensity } \\
{\left[10^{-20} \mathrm{~cm}^{-}\right.} \\
1 / \text { molecule }]\end{array}$ & $\begin{array}{l}\text { line width } \\
\text { fwhm } / \mathrm{cm}^{-1}\end{array}$ & $\mathrm{~T} / \mathrm{K}$ \\
\hline \multicolumn{6}{|l|}{$\mathrm{CO}_{2}$} \\
\hline \multirow[t]{3}{*}{2055.163386} & $1,1^{1}, 0-0,0^{0}, 0$ & P 28 & $\begin{array}{l}1.840 \times 10^{-2} \\
1.573 \times 10^{-2}\end{array}$ & $\begin{array}{l}0.142 \\
0.0996\end{array}$ & $\begin{array}{l}296 \\
500\end{array}$ \\
\hline & & & $1.301 \times 10^{-2}$ & 0.088 & 600 \\
\hline & & & $6.606 \times 10^{-3}$ & 0.067 & 900 \\
\hline \multirow[t]{4}{*}{2056.70104} & $1,1^{1}, 0-0,0^{0}, 0$ & P 26 & $1.950 \times 10^{-2}$ & 0.144 & 296 \\
\hline & & & $1.531 \times 10^{-2}$ & 0.101 & 500 \\
\hline & & & $1.249 \times 10^{-2}$ & 0.089 & 600 \\
\hline & & & $6.088 \times 10^{-3}$ & 0.068 & 900 \\
\hline \multirow[t]{4}{*}{2058.240372} & $1,1^{1}, 0-0,0^{0}, 0$ & $\mathrm{P} 24$ & $2.010 \times 10^{-2}$ & 0.146 & 296 \\
\hline & & & $1.459 \times 10^{-2}$ & 0.102 & 500 \\
\hline & & & $1.159 \times 10^{-2}$ & 0.090 & 600 \\
\hline & & & $5.512 \times 10^{-3}$ & 0.068 & 900 \\
\hline \multicolumn{6}{|l|}{$\mathrm{CO}$} \\
\hline \multirow[t]{4}{*}{2055.4003} & $1-0$ & P21 (51) & 2.501 & 0.100 & 296 \\
\hline & & & 8.55 & 0.070 & 500 \\
\hline & & & 10.81 & 0.062 & 600 \\
\hline & & & 13.79 & 0.0474 & 900 \\
\hline \multirow[t]{2}{*}{2056.0476} & $2-1$ & P15 (51) & $8.618 \times 10^{-4}$ & 0.110 & 296 \\
\hline & & & $8.811 \times 10^{-2}$ & 0.076 & 500 \\
\hline
\end{tabular}




\begin{tabular}{|c|c|c|c|c|c|}
\hline & & & $2.533 \times 10^{-1}$ & 0.066 & 600 \\
\hline & & & 1.271 & 0.050 & 900 \\
\hline \multicolumn{6}{|l|}{$\mathrm{H}_{2} \mathrm{O}$} \\
\hline \multirow[t]{4}{*}{2055.8556} & $0,2,0-0,1,0$ & R $14_{5,10}-13_{4,9} \mathrm{H}_{2} \mathrm{O}$ II & $1.172 \times 10^{-7}$ & 0.106 & 296 \\
\hline & & & $2.078 \times 10^{-4}$ & 0.092 & 500 \\
\hline & & & $1.150 \times 10^{-3}$ & 0.087 & 600 \\
\hline & & & $1.593 \times 10^{-3}$ & 0.078 & 900 \\
\hline \multirow[t]{4}{*}{$2055.91129^{\mathrm{a}}$} & $0,0,1-0,1,0$ & Q $8_{5,4}-8_{5,3} \mathrm{H}_{2} \mathrm{O}$ II & $1.408 \times 10^{-6}$ & 0.104 & 296 \\
\hline & & & $2.077 \times 10^{-4}$ & 0.0934 & 500 \\
\hline & & & $6.299 \times 10^{-4}$ & 0.089 & 600 \\
\hline & & & $3.203 \times 10^{-3}$ & 0.080 & 900 \\
\hline \multirow[t]{4}{*}{$2057.41122^{b}$} & $0,0,1-0,1,0$ & Q $8_{5,3}-8_{5,4} \mathrm{H}_{2} \mathrm{O} \mathrm{I}$ & $4.236 \times 10^{-6}$ & 0.110 & 296 \\
\hline & & & $6.242 \times 10^{-4}$ & 0.094 & 500 \\
\hline & & & $1.893 \times 10^{-3}$ & 0.09 & 600 \\
\hline & & & $9.622 \times 10^{-3}$ & 0.08 & 900 \\
\hline \multirow[t]{4}{*}{$2057.41933^{b}$} & $0,1,0-0,0,0 \mathrm{c}$ & R $15_{5,11}-15_{4,10}$ & $1.666 \times 10^{-5}$ & 0.101 & 296 \\
\hline & & & $2.273 \times 10^{-3}$ & 0.0914 & 500 \\
\hline & & & $6.765 \times 10^{-3}$ & 0.088 & 600 \\
\hline & & & $3.335 \times 10^{-2}$ & 0.081 & 900 \\
\hline \multirow[t]{4}{*}{2058.49501} & $0,0,1-0,1,0$ & Q $7_{5,3}-7_{5,2}$ & $1.210 \times 10^{-5}$ & 0.1044 & 296 \\
\hline & & & $1.210 \times 10^{-3}$ & 0.0916 & 500 \\
\hline & & & $3.341 \times 10^{-3}$ & 0.0874 & 600 \\
\hline & & & $1.453 \times 10^{-2}$ & 0.079 & 900 \\
\hline
\end{tabular}


${ }^{\text {a }}$ Components of partially resolved asymmetric water feature, one component may be identified using the HITRAN [14] database, both are included in HITEMP2010 [15]

${ }^{b}$ These two lines cannot be resolved and contribute to the strongest water feature (b) seen in the spectra

${ }^{\mathrm{c}}$ This line belongs to the $\mathrm{H}_{2}{ }^{17} \mathrm{O}$ isotopologue 
Table 3

Parameters used for the calculated transmission spectra

\begin{tabular}{|l|l|l|l|}
\hline Path length & Partial pressure/Torr & Partial pressure/Torr & Partial pressure/Torr \\
carbon monoxide & carbon dioxide & water \\
\hline $1 \mathrm{~m}$ & 0.1 & 3.3 & 10 \\
\hline $0.882 \mathrm{~m}$ & 0.114 & 3.74 & 11.3 \\
\hline
\end{tabular}




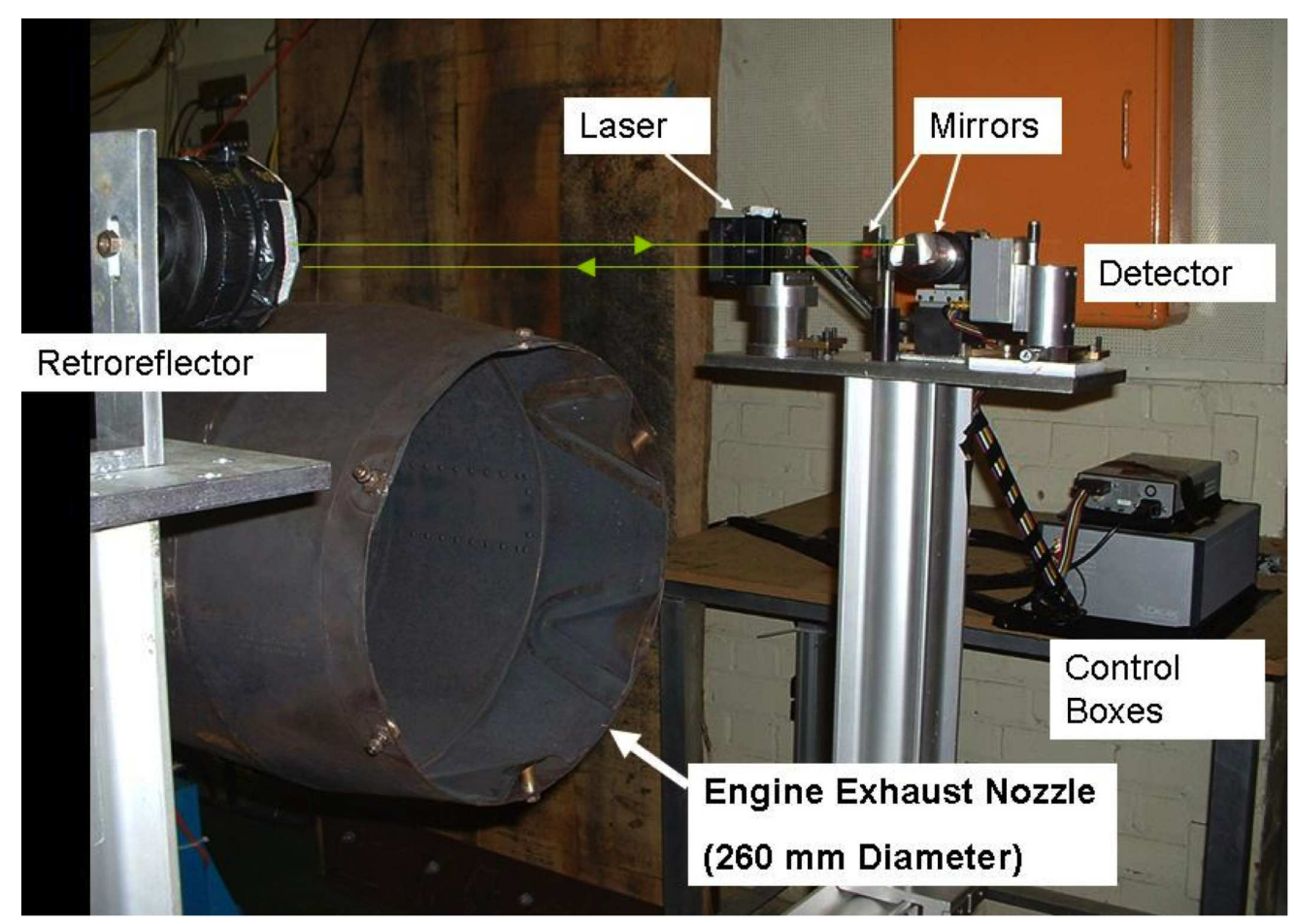

$752 \times 533 \mathrm{~mm}(72 \times 72$ DPI $)$

2

3

4

5

6
7

8 


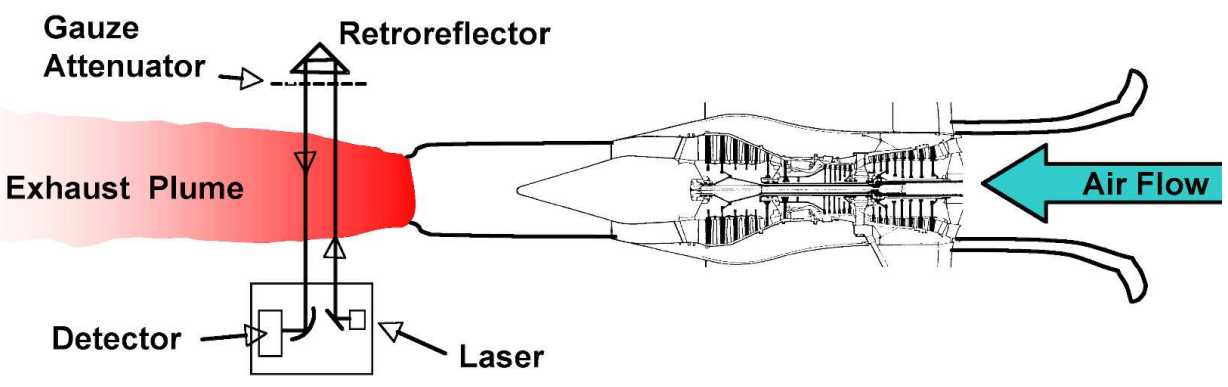

$146 \times 47 \mathrm{~mm}(600 \times 600 \mathrm{DPI})$ 


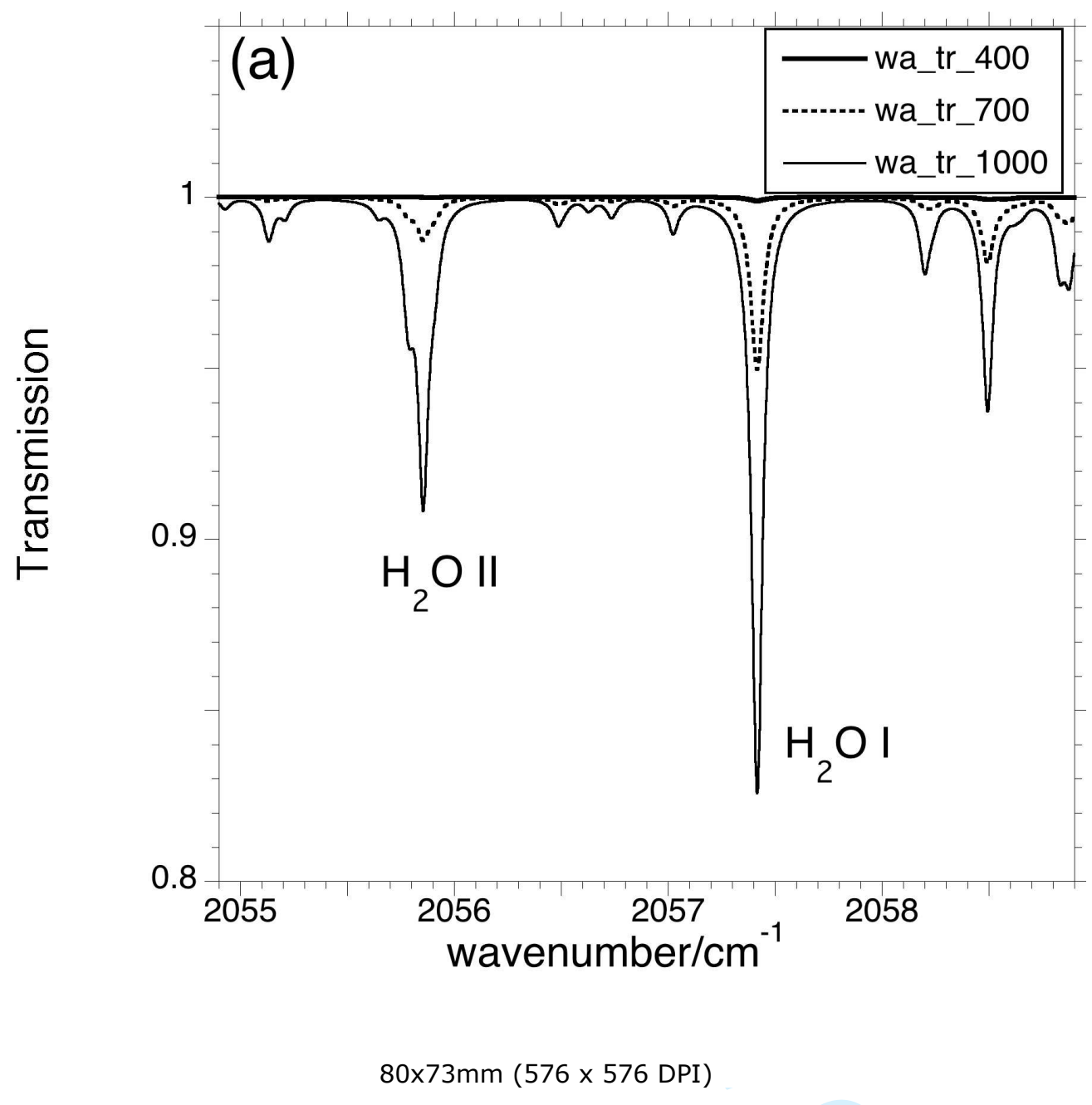

1

2

3

4

5

6

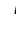

10

11

12

13

14

15

16

17

18

19

20

21

22

23

24

25

26

27

28

29

30

31

32

33

34

35

36

37

38

39

40

41

42

43

44

45

46

47

48

49

50

51

52

53

54

55

56

57

58

59

60 hysics

$80 \times 73 \mathrm{~mm}(576 \times 576 \mathrm{DPI})$

URL: http://mc.manuscriptcentral.com/tandf/tmph 


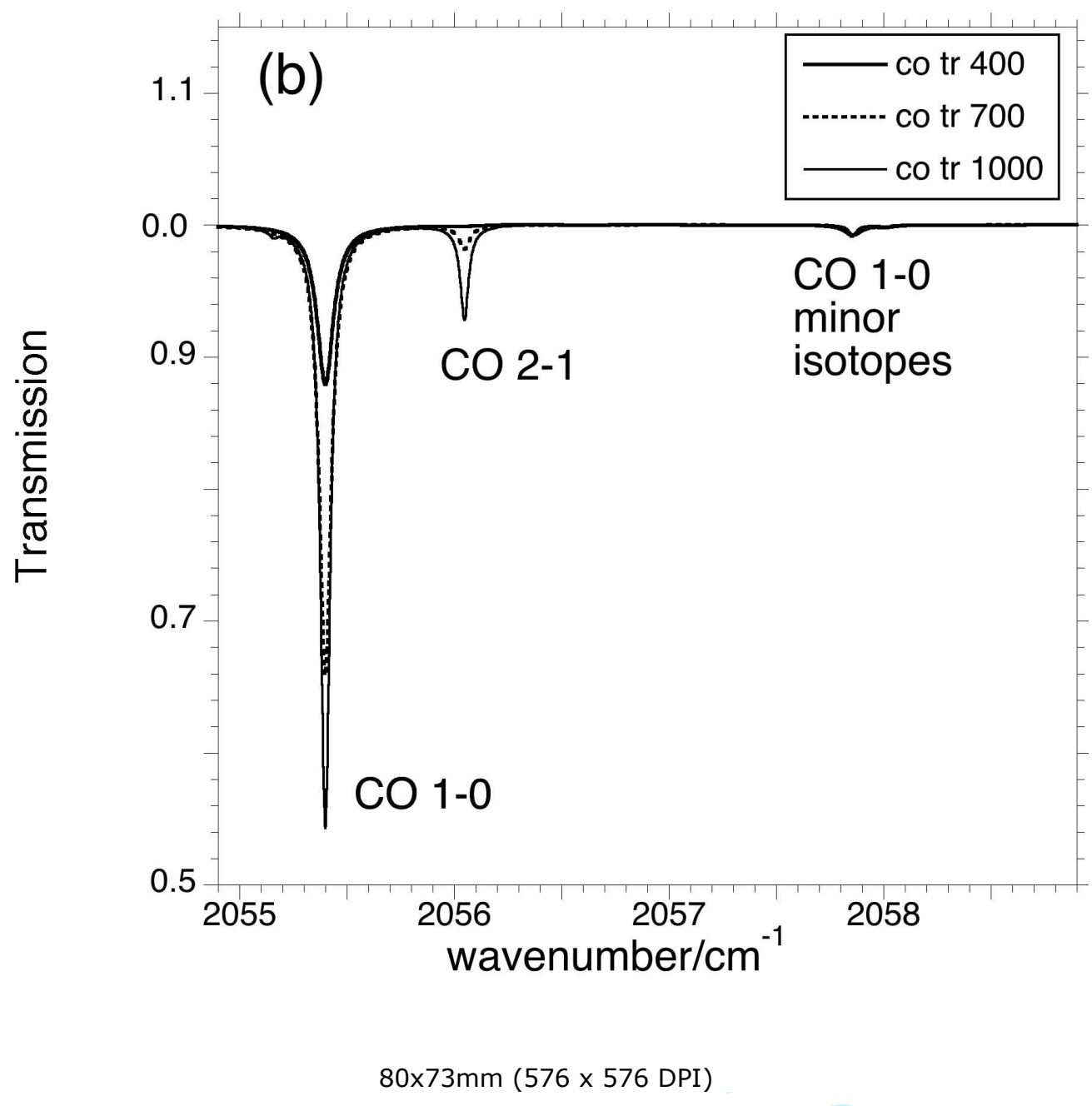

URL: http://mc.manuscriptcentral.com/tandf/tmph 


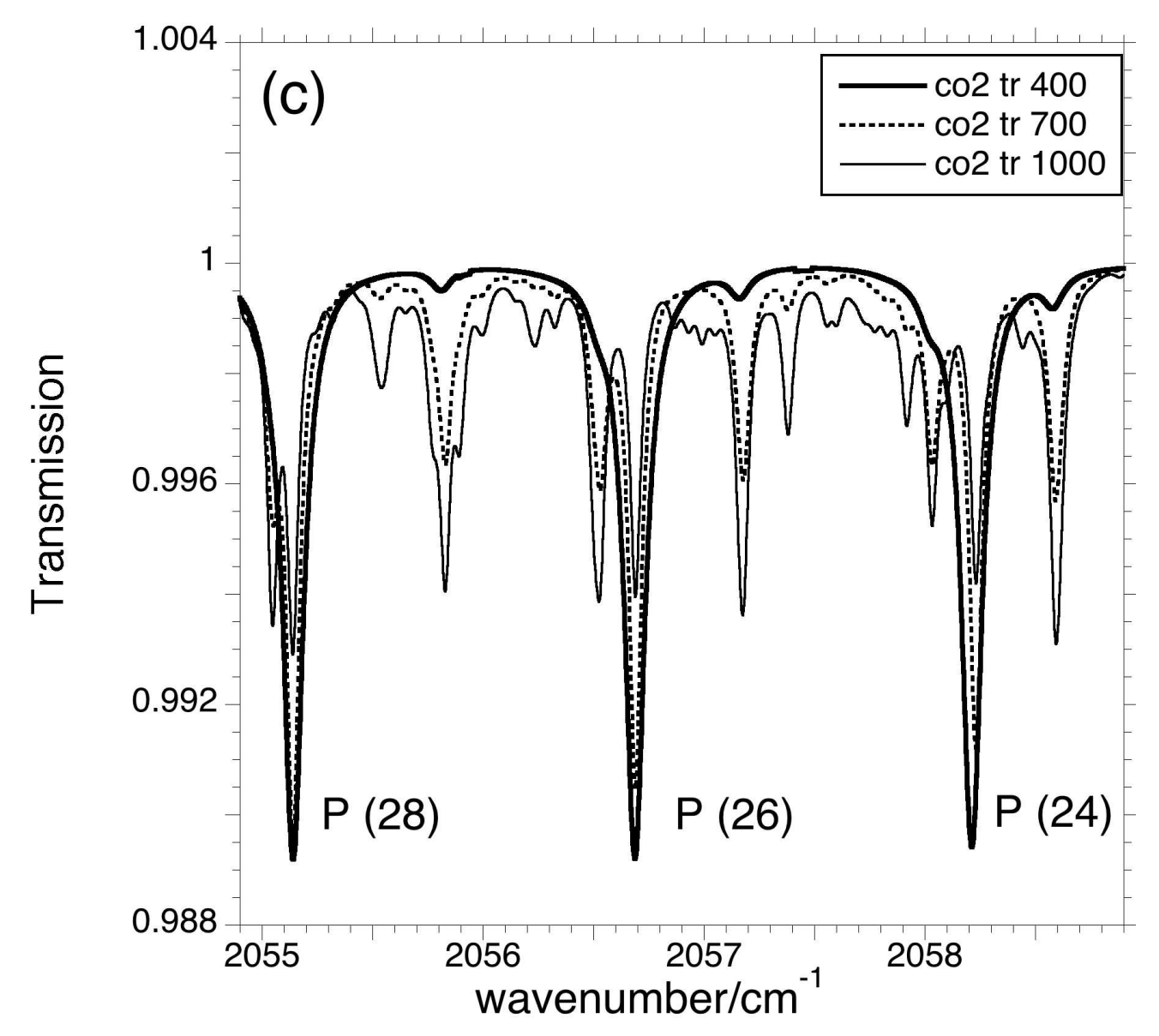

$80 \times 73 \mathrm{~mm}(576 \times 576$ DPI $)$ 


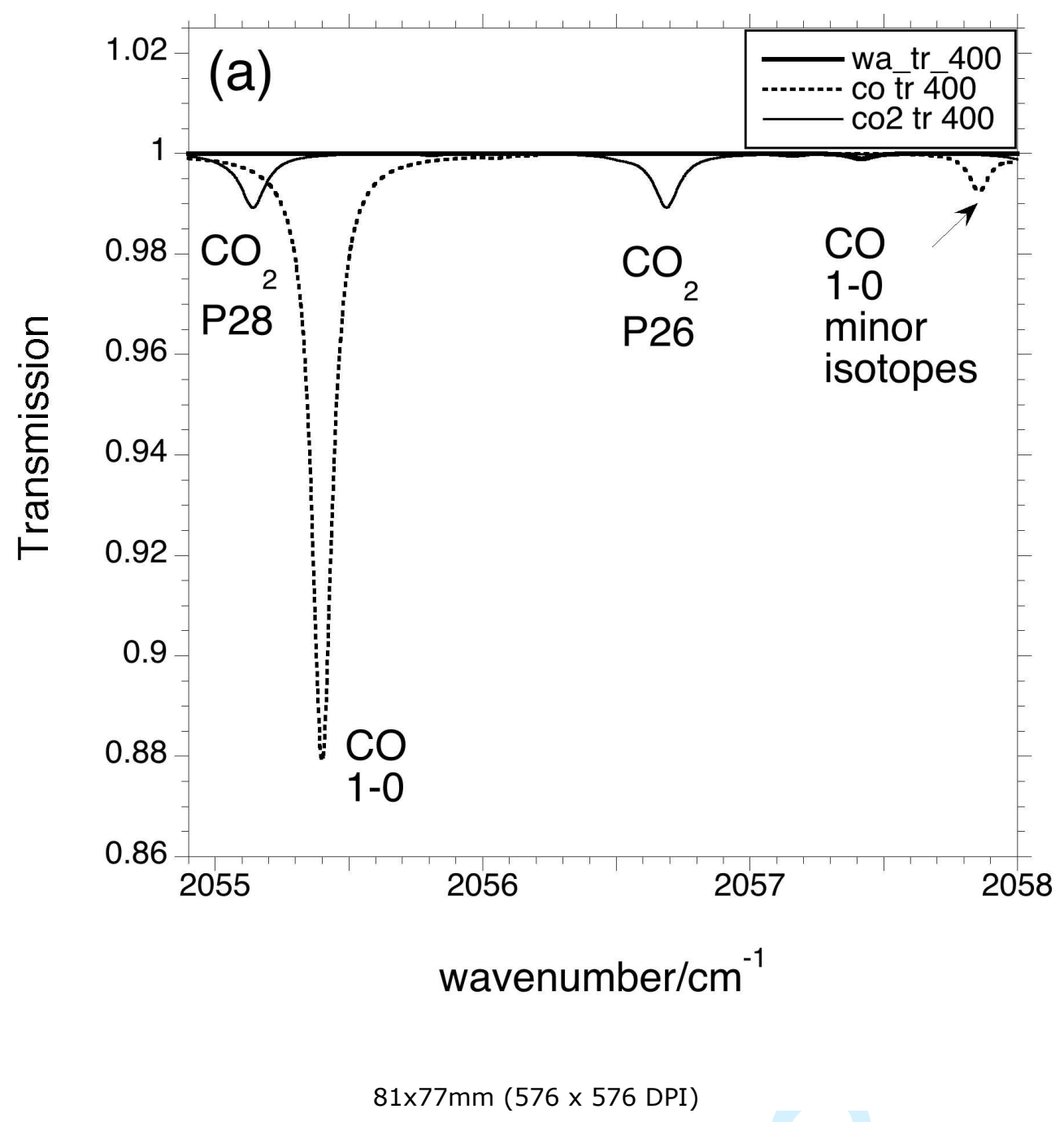

URL: http://mc.manuscriptcentral.com/tandf/tmph 


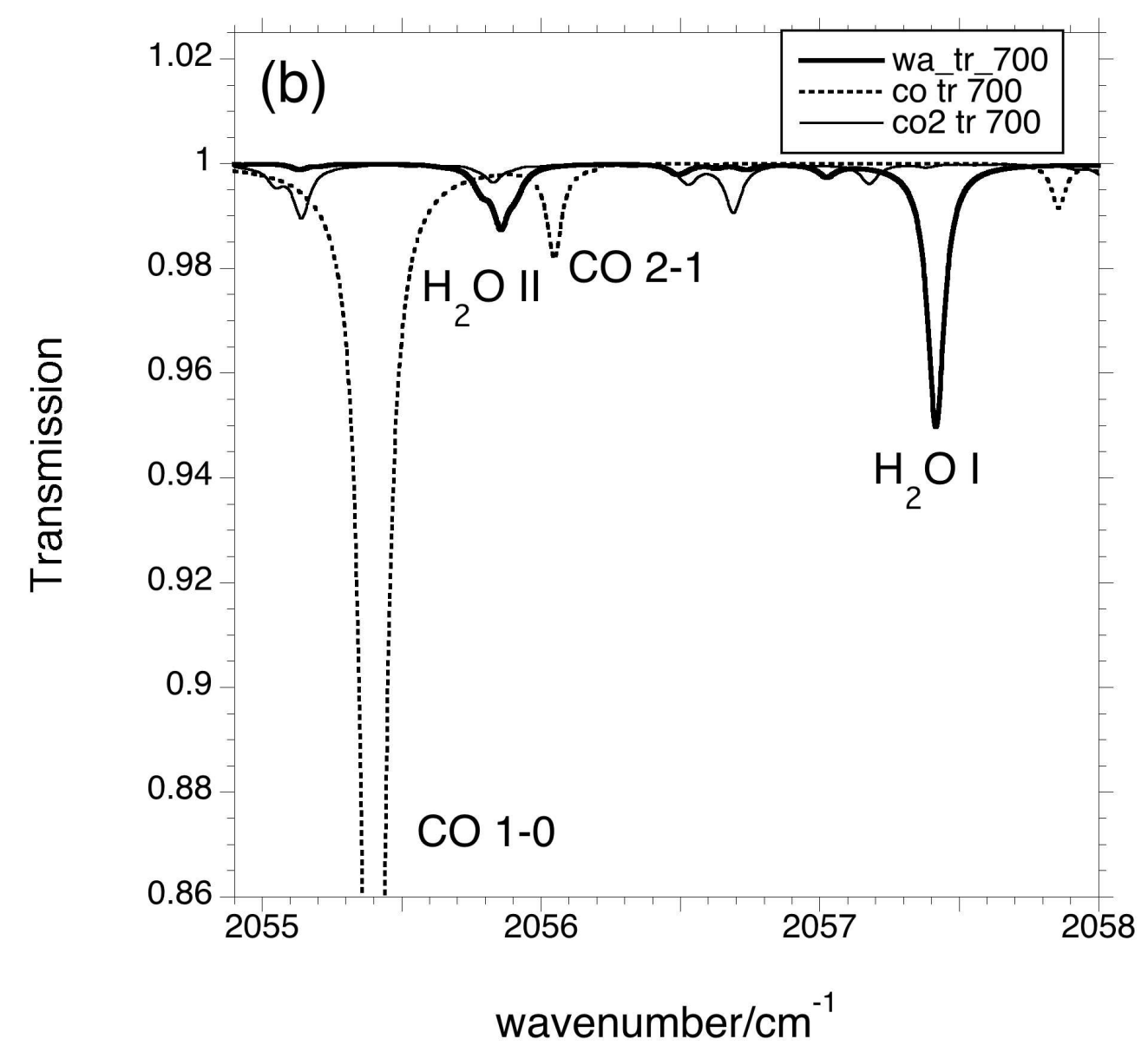

$83 \times 77 \mathrm{~mm}(576 \times 576$ DPI $)$ 


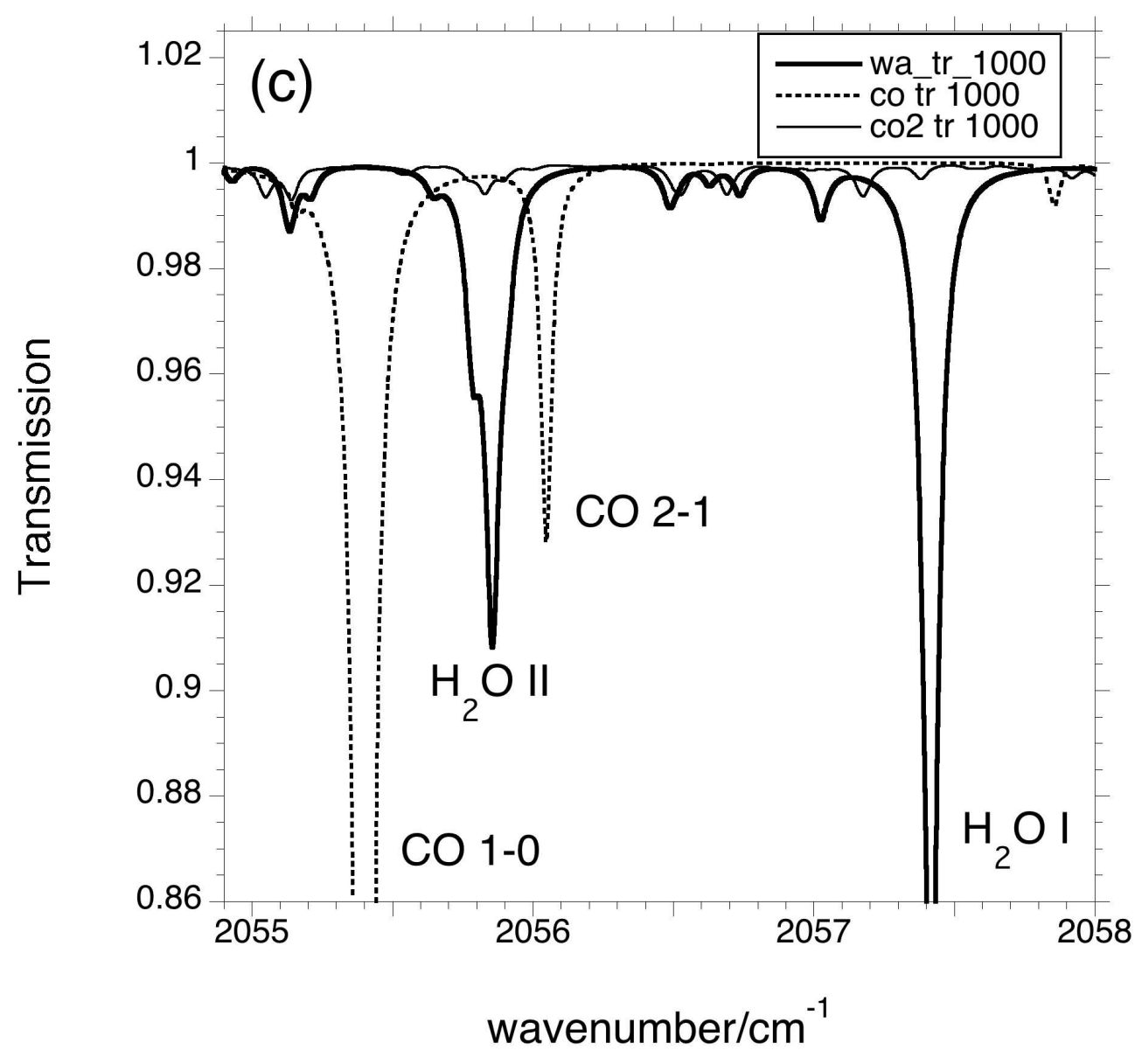

$83 \times 77 \mathrm{~mm}(576 \times 576$ DPI $)$ 


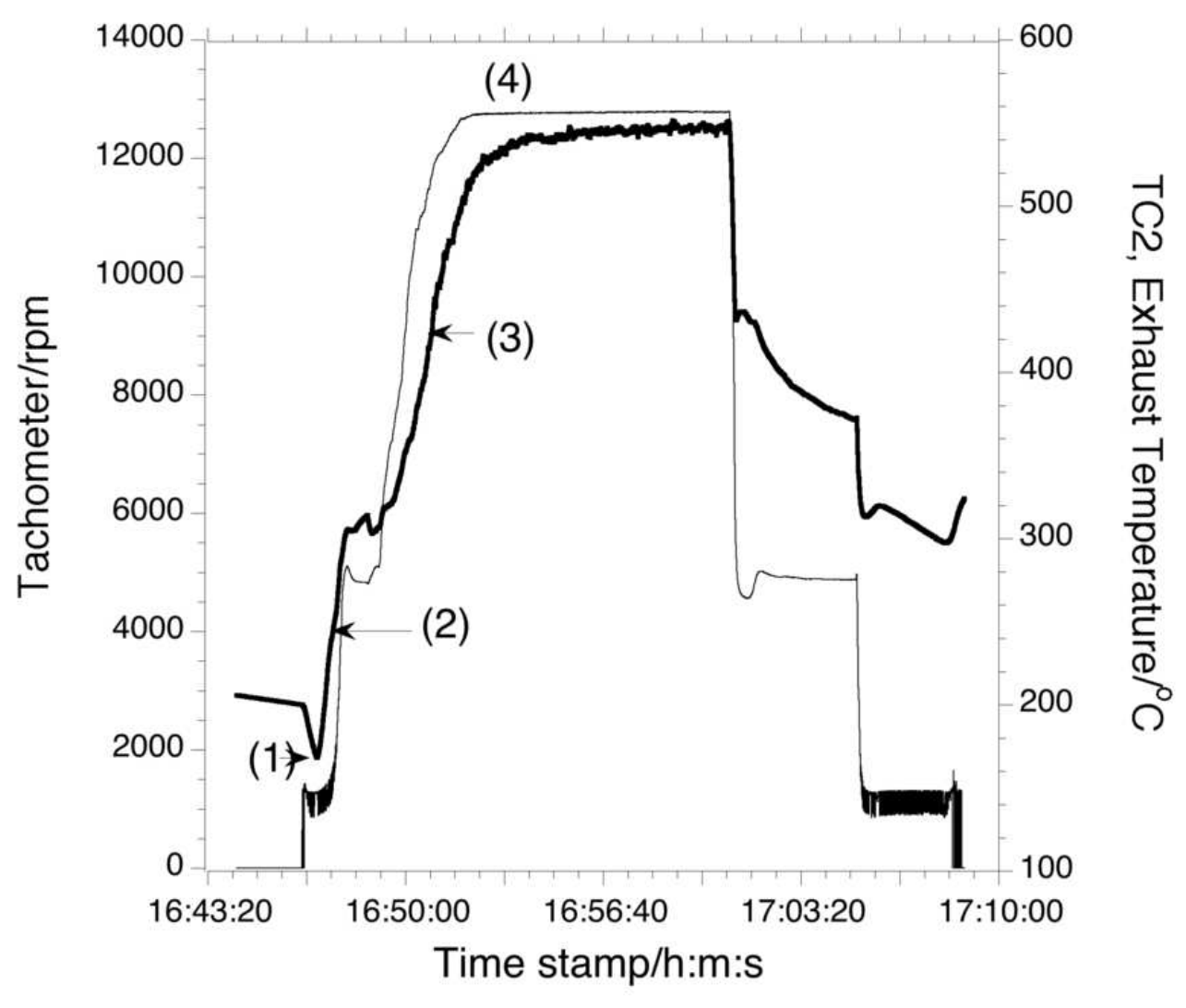

$75 \times 61 \mathrm{~mm}(300 \times 300$ DPI $)$ 


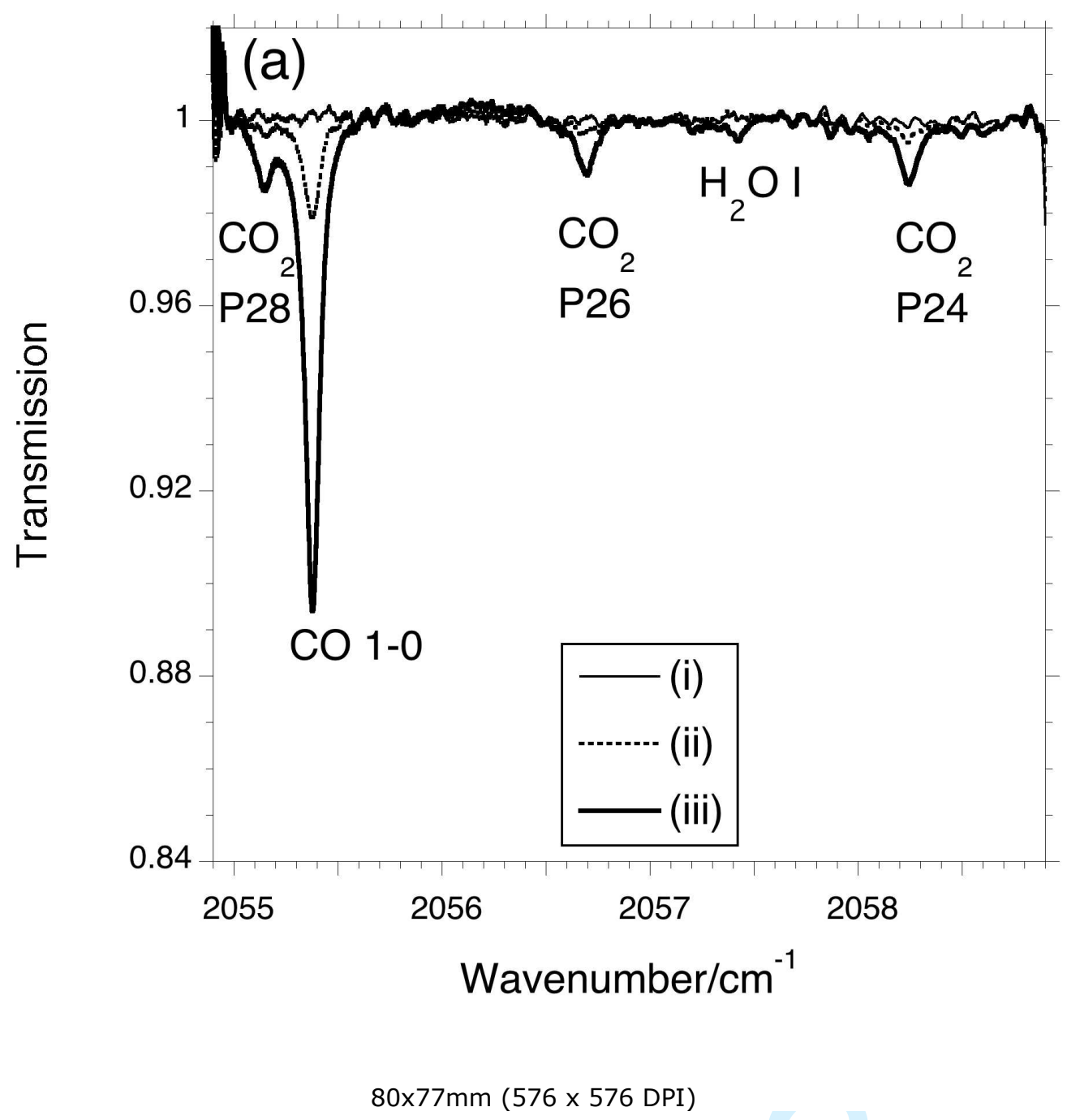

URL: http://mc.manuscriptcentral.com/tandf/tmph 


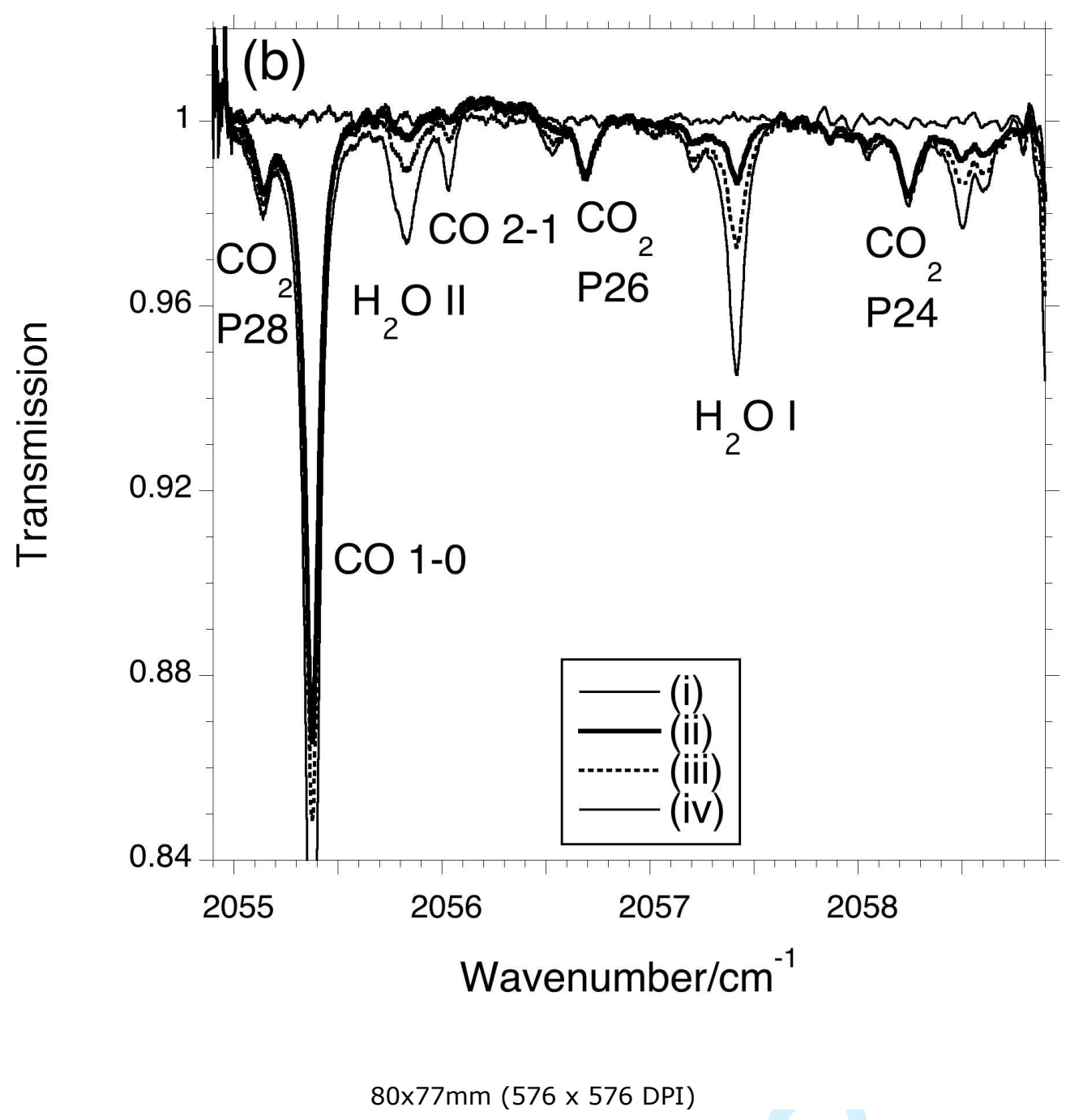

URL: http://mc.manuscriptcentral.com/tandf/tmph 


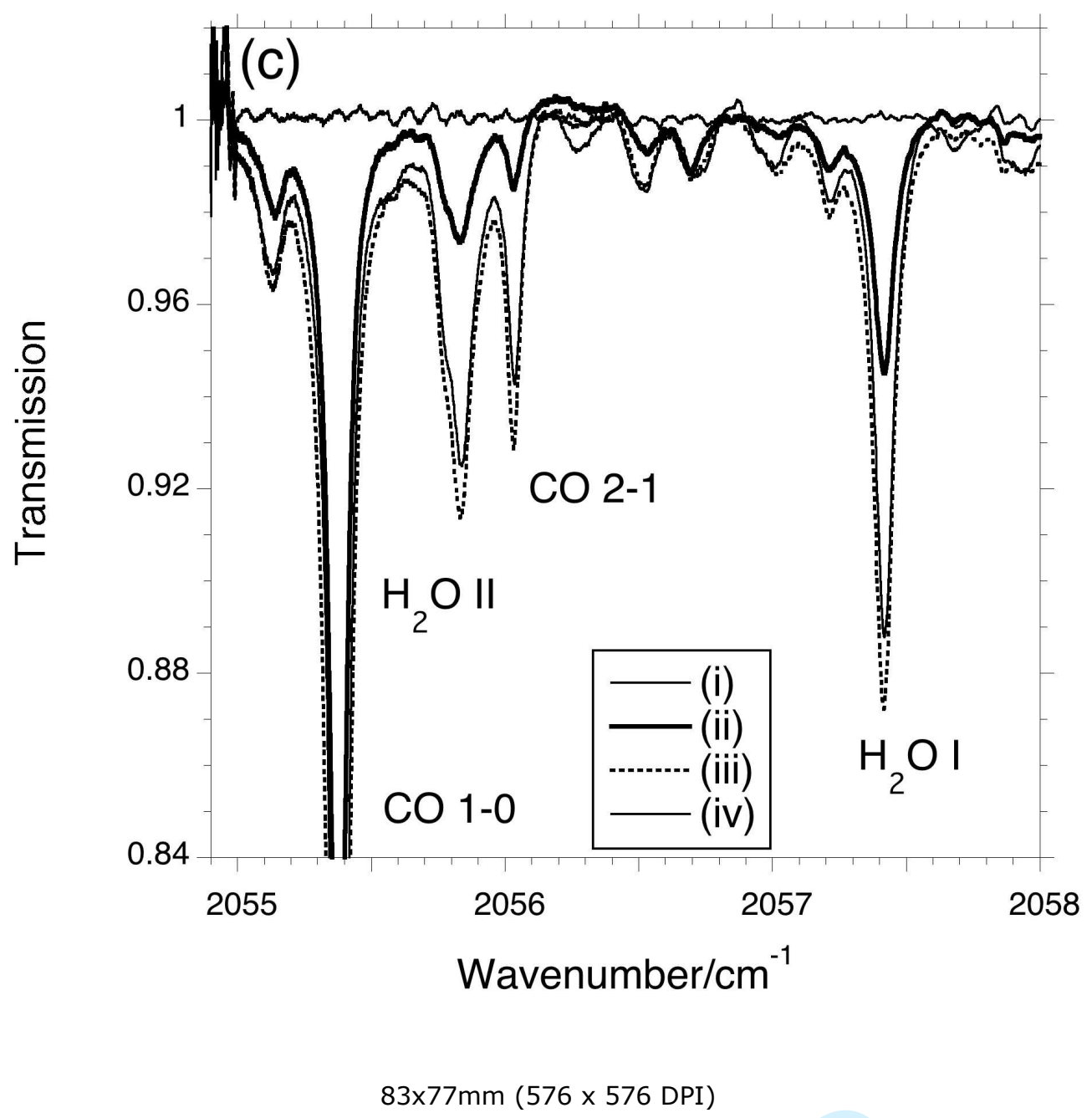

URL: http://mc.manuscriptcentral.com/tandf/tmph 


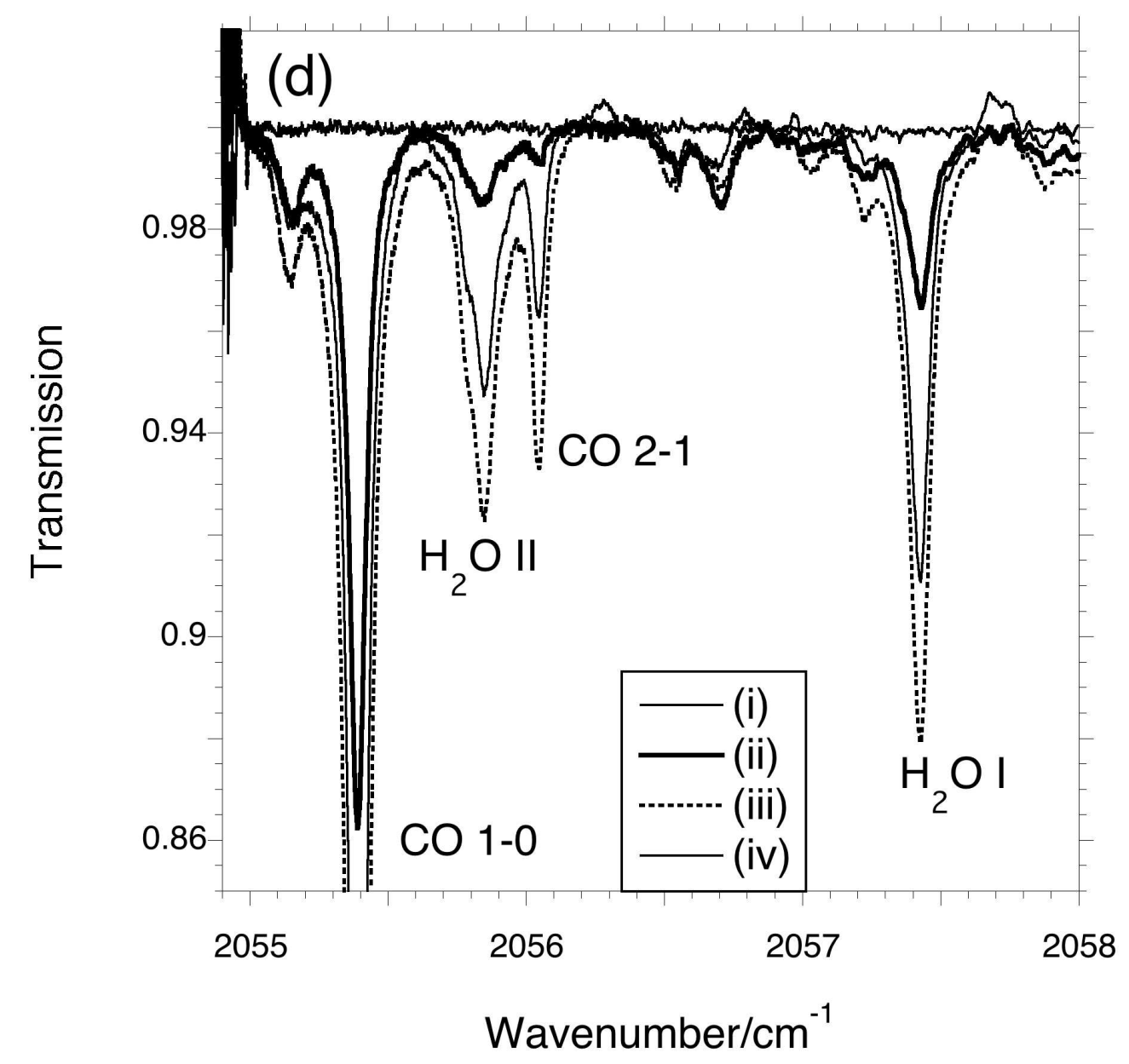

$81 \times 78 m m(576 \times 576$ DPI) 


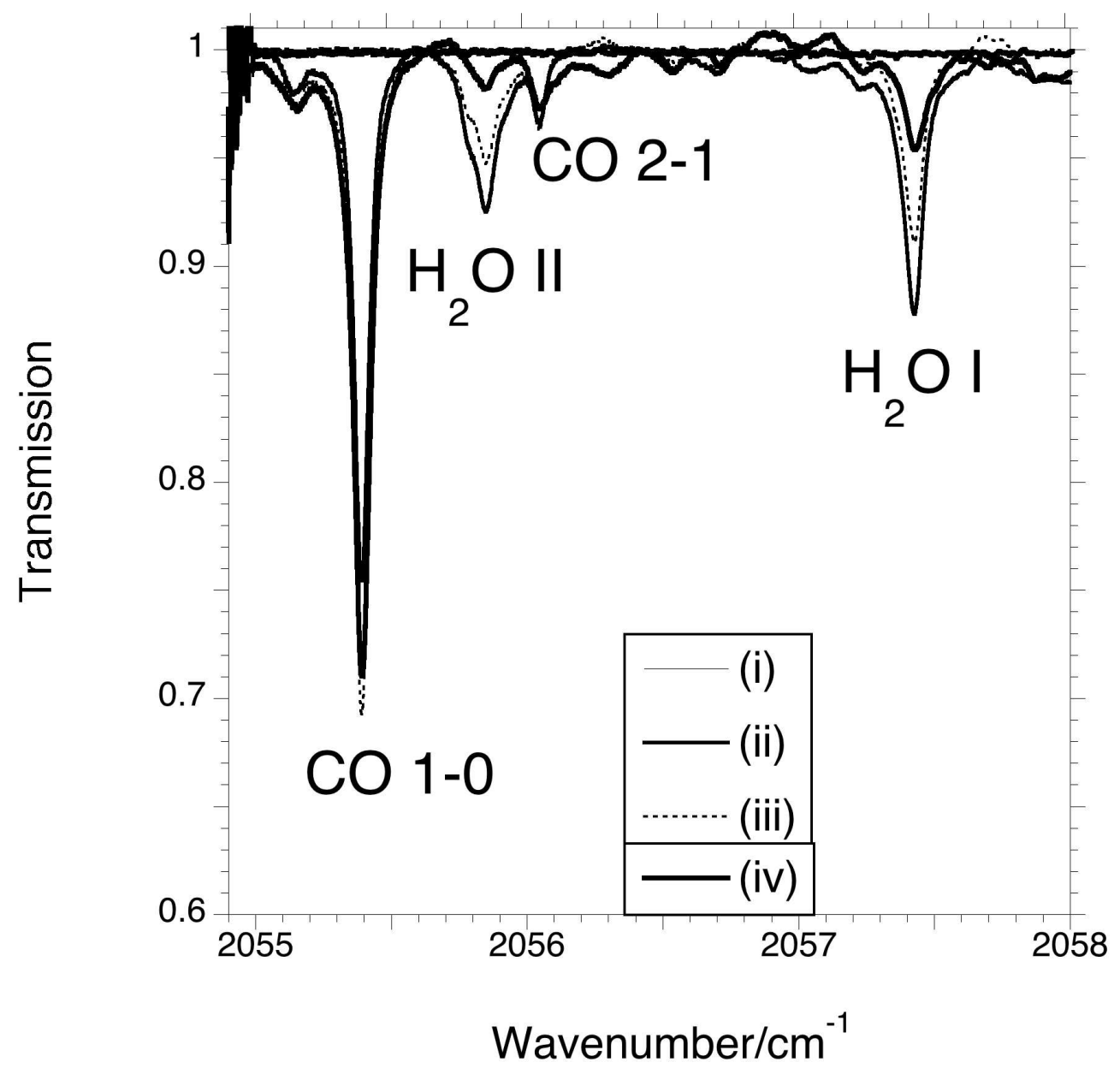

$79 \times 77 \mathrm{~mm}(576 \times 576$ DPI $)$ 


1
2
3
4
5
6
7
8
9
10
11
12
13
14
15
16
17
18
19
20
21
22
23
24
25
26
27
28
29
30
31
32
33
34
35
36
37
38
39
40
41
42
43
40
45
49
50
51
52
53
55
50

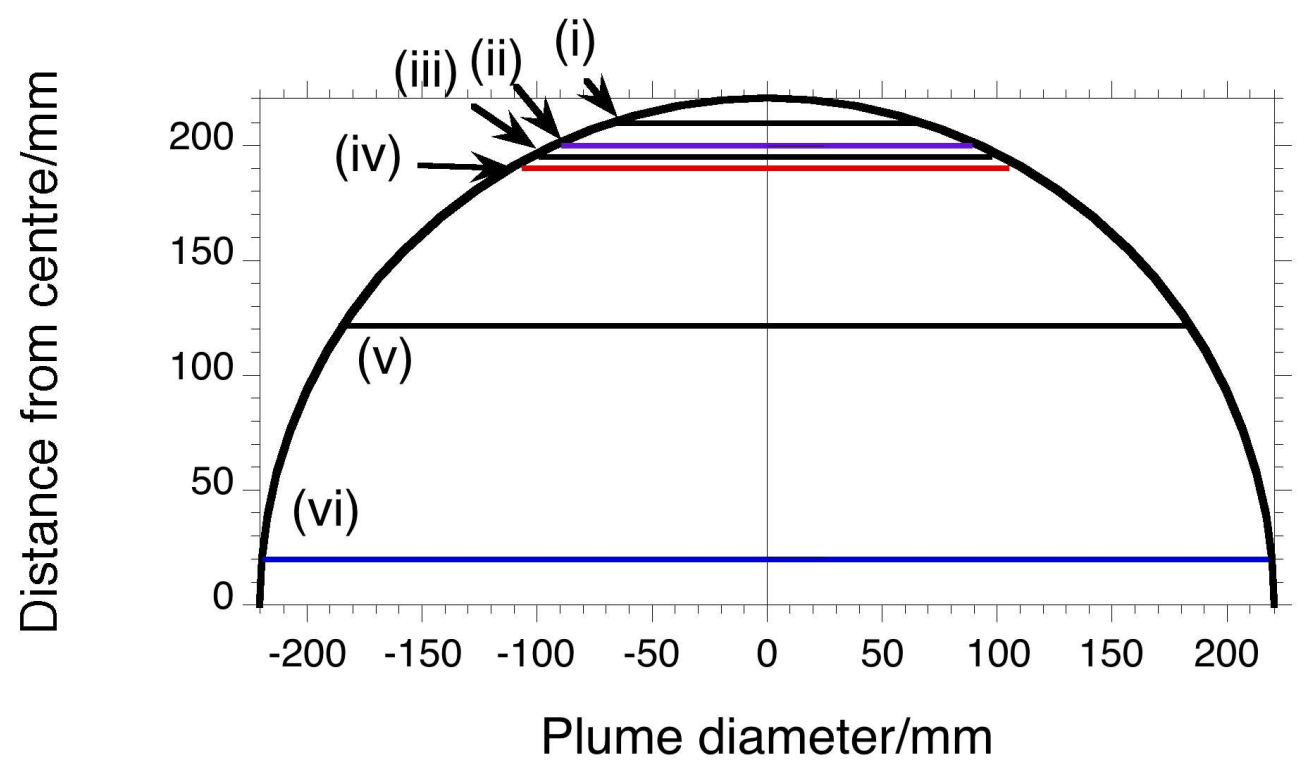

$81 \times 48 m m(576 \times 576$ DPI) 


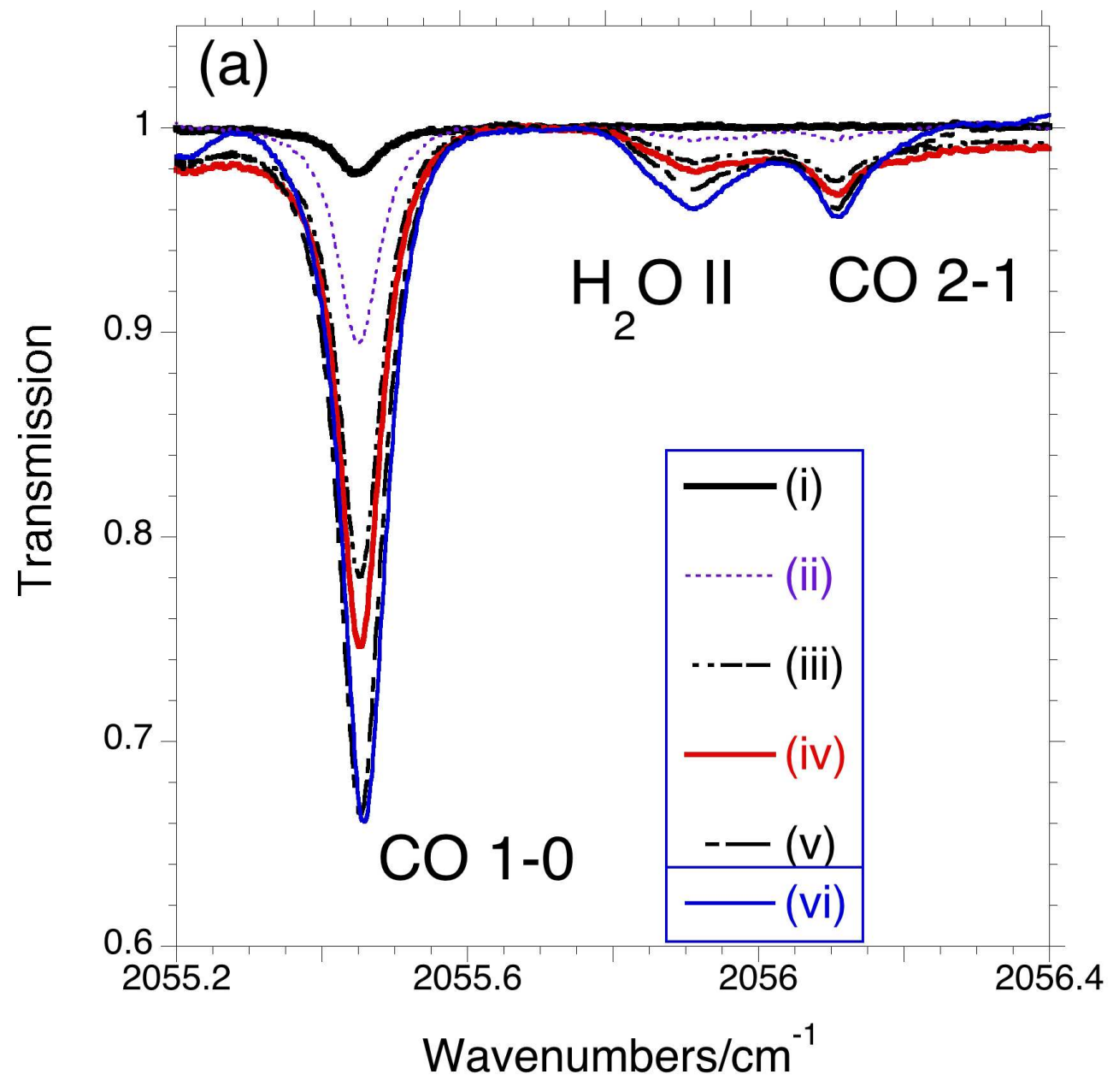

$76 \times 75 \mathrm{~mm}(576 \times 576 \mathrm{DPI})$ 


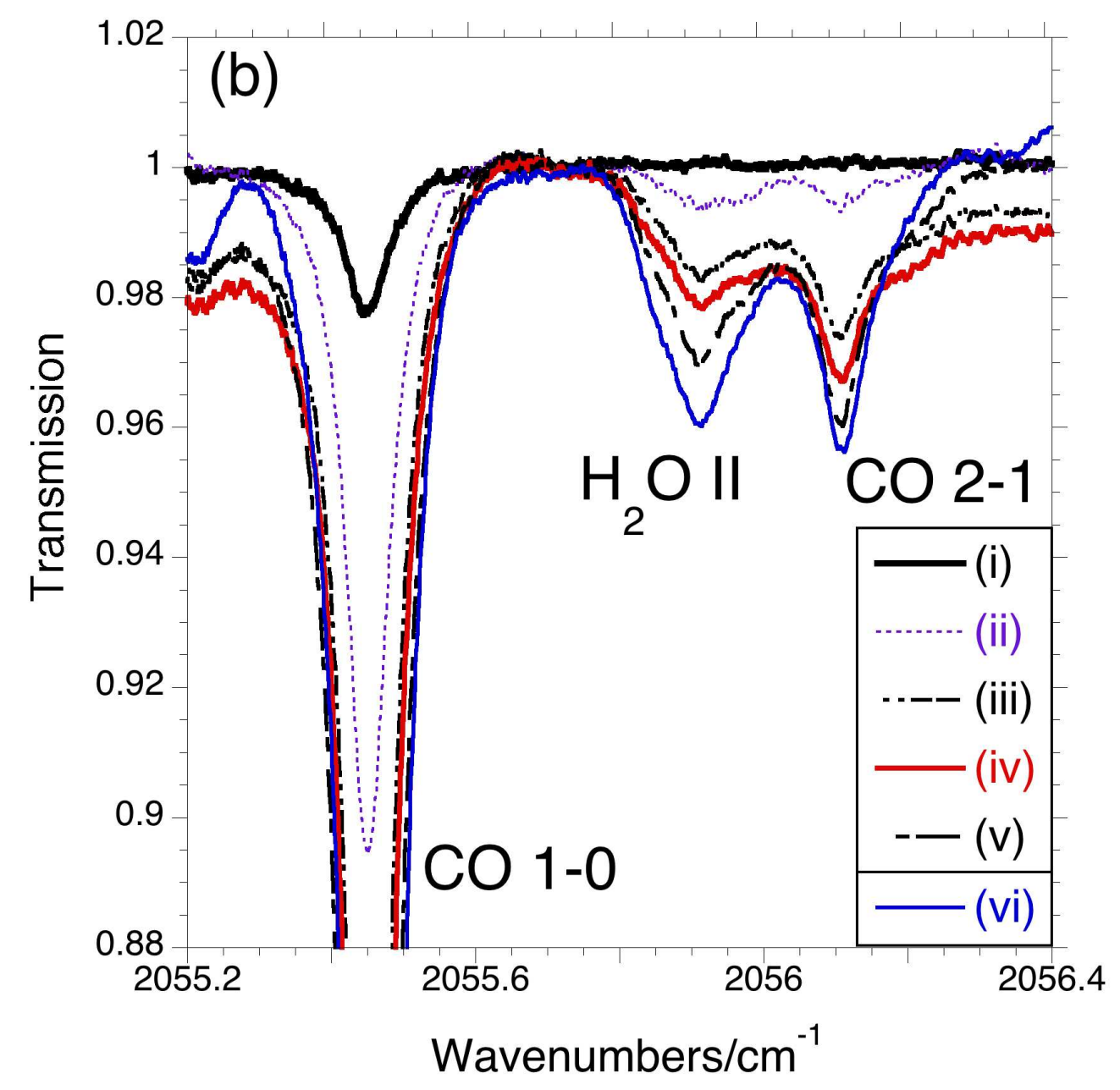

$76 \times 75 \mathrm{~mm}(576 \times 576$ DPI $)$ 


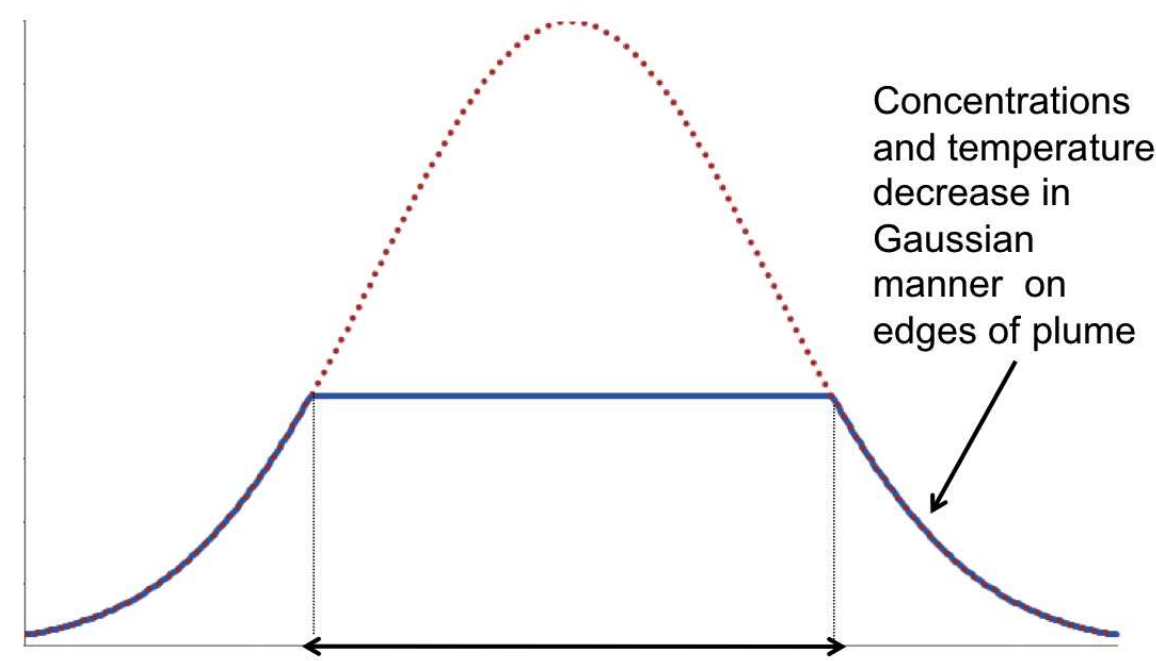

Homogeneous region - approx. diameter of final exhaust nozzle

$431 \times 309 \mathrm{~mm}(72 \times 72$ DPI $)$ 